\title{
Electrocatalysts for hydrogen oxidation and evolution reactions
}

\author{
Siqi Lu and Zhongbin Zhuang*
}

\begin{abstract}
The hydrogen economy is a clean, efficient, and sustainable energy system that delivers energy using hydrogen. Electrolyzers are used to generate hydrogen, and fuel cells consume hydrogen as a fuel. These devices rely on hydrogen evolution and oxidation reactions. Catalysts are required to accelerate the reactions. $\mathrm{Pt}$ is the best hydrogen oxidation/evolution reaction (HOR/HER) catalyst to date. However, the scarcity of Pt hinders its applications. Various processes have been developed to increase the catalyst activity in order to reduce the amount of $\mathrm{Pt}$, or to develop non-precious metal catalysts to replace Pt. In this review, we focus on electrocatalysts for the hydrogen oxidation and evolution reactions. The reaction mechanism, factors influencing the catalyst activity, and the influence of the electrolyte (acid $v$ s. base) are discussed. The recent advances in catalyst development, especially of non-precious metal catalysts, are also summarized. Due to the different reaction conditions and catalytic activities associated with the different electrolytes, the catalysts are classified into two categories: active in acid or in base.
\end{abstract}

Keywords: electrocatalyst, hydrogen, nanomaterials, fuel cell, electrolyzer

\section{INTRODUCTION}

Energy problems have become more and more prevalent in recent decades. The progressive development of modern society continues to require more and more energy. However, fossil fuels still represent the major energy source. Many environmental problems, such as air pollution, are associated with the combustion of fossil fuels. Thus, clean and sustainable fuels are desired. In the 1970s, Bockris [1-3] presented a futuristic picture of the use of hydrogen as a fuel (Fig. 1). Hydrogen is a clean fuel and only water is generated by its combustion. The prospective use of hydrogen in motor vehicles would preclude $\mathrm{CO}_{2}$ emission from the tail pipe. Hydrogen can be obtained from the olefin industry or water-gas shift reaction. However, a cleaner and more sustainable way to obtain hydrogen is by splitting water electrochemically or photoelectrochemically. An electrolyzer or a photoelectrolyzer is used to split water. The half reaction for the generation of hydrogen from water is the hydrogen evolution reaction (HER), in which water is reduced and hydrogen is generated. Hydrogen is the carrier of energy, and it can be delivered to the location where energy is required. Hydrogen can be used as a normal fuel in the internal combustion engine, similar to fossil fuels. More importantly, hydrogen can be used in fuel cells that directly convert chemical energy to electricity. The efficiency of the internal combustion engine is limited by the Carnot cycle, and is generally $30 \%$. The efficiency of fuel cells is not limited by the Carnot cycle, and often as high as $60 \%$. In fuel cells, hydrogen undergoes an oxidation process and generates protons; this reaction is called the hydrogen oxidation reaction (HOR). Fuel cells can be used on various scales, from power stations to automobiles, and even in portable devices. In 2015, Toyota introduced a line of commercial fuel cell cars called Mirai, portending the introduction of the fuel cell into our daily life. Based on electrolyzers and fuel cells, the hydrogen economy can be realized. This is a future energy system that is clean and

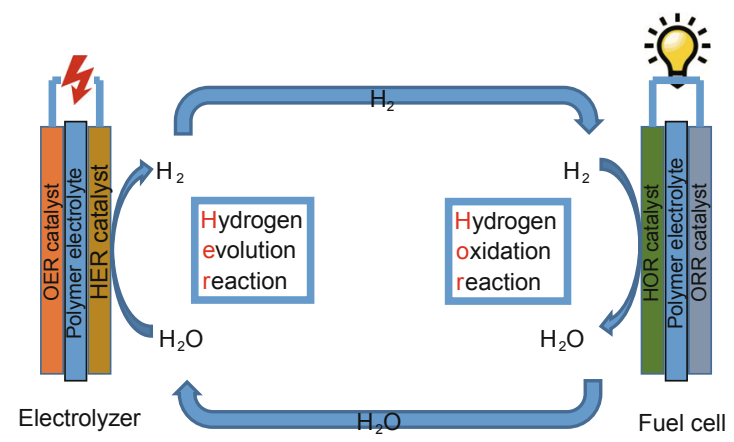

Figure 1 Schematic of hydrogen cycle in the hydrogen economy.

State Key Lab of Organic-Inorganic Composites and College of Chemical Engineering, Beijing University of Chemical Technology, Beijing 100029, China

*Corresponding author (email: zhuangzb@mail.buct.edu.cn) 
sustainable, and is anticipated to enhance further devolvement of the human society.

A key component of fuel cells and electrolyzers is the catalyst. The HOR/HER is kinetically impossible without a catalyst. The other half reaction in fuel cells or electrolyzers is the oxygen oxidation reaction (ORR) or oxygen evolution reaction (OER). There are several excellent reviews that discuss ORR and OER catalysts [4-9]. Thus, this review focuses on the hydrogen electrode. In a modern fuel cell or electrolyzer, an ion conductive membrane is often required to separate the anode and cathode. Based on the conductive species, the membranes can be classified into two types, proton exchange membranes (PEMs) that conduct protons [10] and anion exchange membranes (AEMs) that conduct hydroxides [11]. This allows the fuel cells or electrolyzers to work under either acidic or basic environment. Thus, the HOR/HER can occur in acid (Equation (1)) or base (Equation (2)):

$$
\begin{gathered}
2 \mathrm{H}^{+}+2 \mathrm{e}^{-} \leftrightarrow \mathrm{H}_{2}, \\
2 \mathrm{H}_{2} \mathrm{O}+2 \mathrm{e}^{-} \leftrightarrow \mathrm{H}_{2}+2 \mathrm{OH}^{-} .
\end{gathered}
$$

Both forward reactions correspond to the hydrogen evolution reaction and the backward reactions correspond to the hydrogen oxidation reaction. The standard equilibrium potential is $0 \mathrm{~V}$ in acid by definition. Platinum is the most active HOR/HER catalyst to date. However, the scarcity of Pt has hindered realistic application of fuel cells and electrolyzers. Thus, it is highly desirable to reduce the amount of Pt by increasing the catalyst activity or to develop platinum group metal (PGM)-free catalysts to replace Pt. To improve the activity of the catalyst, an understanding of the reaction mechanism is indispensable. Heterogeneous catalysts are commonly used for the HOR/HER. The active species adsorb/desorb at the catalyst surface and also exchange electrons. However, it is difficult to investigate the surface condition of the catalyst in situ due to the presence of the electrolyte. The HOR/HER is the simplest electrochemical reaction, and is also a good model for evaluating the electrochemical behavior of the active species on the surface of the catalysts. This system can also help us understand other complex electrochemical reactions. Moreover, it has been found that the activity of the catalyst is also influenced by the electrolyte. For the same catalyst, the activity varies in acid and base. As a benefit of the recent advances, the parameters influencing the activity of HOR/HER catalysts have been defined, and catalysts with enhanced activity have been reported. Modified Pt species, such as Pt alloys, have shown superior activity relative to the pris- tine Pt. Several PGM-free catalysts have been developed as prospective Pt replacements. There are not many choices of catalysts for use under harsh acidic conditions. Most metals and compounds are dissolved in acid. However, recent studies show that some metal dichalcogenides and phosphides are stable in acid and exhibit impressive HER activity. In contrast, the basic environment is less harsh and there are some non-precious metals that are functional under basic conditions. Several non-precious metal catalysts for both the HOR and HER have been reported.

In this review, we focus on the HOR/HER reactions, and discuss measurements of the activity of HOR/HER catalysts, the catalytic mechanism, the parameters for describing the activity, and the influence of the electrolyte (acid $v s$. base). Finally, we summarize the recent advances in catalyst development, mainly for PGM-free catalysts, in acid and base, respectively.

\section{MEASUREMENT OF THE HOR/HER ACTIVITIES}

The HOR/HER activity of the catalysts can generally be measured in an electrochemical cell using the standard three-electrode system. $\mathrm{H}_{2} \mathrm{SO}_{4}$ or $\mathrm{HClO}_{4}$ is used as the electrolyte to mimic the acidic condition, and $\mathrm{KOH}$ or $\mathrm{NaOH}$ is used to mimic the basic condition. The exchange current density $\left(i_{0}\right)$, the kinetic current density $\left(i_{\mathrm{k}}\right)$ at a fixed overpotential, or the overpotential required to achieve a certain current density is generally used as a parameter to judge the activity of different catalysts. Cyclic voltammetry (CV) or the linear sweep voltammetry (LSV) is employed to record the electrochemical behavior of the catalysts. In general, the rotating disk electrode ( $\mathrm{RDE}$ ) technique is required for HOR measurement due to the low solubility of $\mathrm{H}_{2}$ in the electrolyte. The mass transport can be improved by the RDE technique, and the kinetics of the catalysts can be obtained from the mixed kinetic-diffusion control region. The measured overall current $(i)$ is a combination of the kinetic $\left(i_{\mathrm{k}}\right)$ and diffusional $\left(i_{\mathrm{d}}\right)$ components, and can be described by the Koutecky-Levich equation (Equation (3)):

$$
\frac{1}{i}=\frac{1}{i_{\mathrm{k}}}+\frac{1}{i_{\mathrm{d}}} .
$$

Under infinitely fast reaction kinetics, the overpotential is completely under diffusional control; the diffusional-controlled overpotential $\left(\eta_{\text {diffusion }}\right)$ can be described by Equation (4):

$$
\eta_{\text {diffusion }}=-\frac{R T}{2 F}\left(1-\frac{i_{\mathrm{d}}}{i_{1}}\right) .
$$


Here, $R$ is the universal gas constant, $T$ is the temperature, $F$ is Faraday's constant, and $i_{1}$ is the $\mathrm{H}_{2}$-limiting current density. In the RDE measurement, $i_{1}$ is proportional to the square root of the rotating speed ( $\omega$ in rpm), as indicated by the Levich equation (Equation (5)):

$$
i_{1}=0.2 n F C_{\mathrm{H}_{2}} D_{\mathrm{H}_{2}}^{2 / 3} v^{-1 / 6} \omega^{1 / 2}=B C_{\mathrm{H}_{2}} \omega^{1 / 2} \text {. }
$$

Here, $n$ is the number of electrons transferred ( $n=2$ for HOR); $C_{\mathrm{H}_{2}}$ and $D_{\mathrm{H}_{2}}$ are the solubility and diffusivity of $\mathrm{H}_{2}$ in the electrolyte, respectively, and $v$ is the kinetic viscosity of the electrolyte. $B$ is the Levich constant, which is a function of $n, F, D_{\mathrm{H}_{2}}$ and $v$. For the HOR in aqueous electrolyte, $B C_{\mathrm{H}_{2}}$ is roughly $0.0687 \mathrm{~mA} \mathrm{rpm}{ }^{1 / 2} \mathrm{~cm}^{-2}(\omega$ in $\mathrm{rpm}$ ) or $0.205 \mathrm{~mA}$ $\mathrm{s}^{1 / 2} \mathrm{~cm}^{-2}\left(\omega\right.$ in rds s$\left.{ }^{-1}\right)[12,13]$. Thus, the kinetic component $\left(i_{\mathrm{k}}\right)$, which corresponds to the activity of the catalyst, can be extracted from the polarization curve.

For the measurement of the kinetic current in the HER component, the influence of the diffusional component is negligible because water is the most abundant reactant. Thus, the measured current can be directly used as $i_{\mathrm{k}}$. It should be noted that it is necessary to remove the bubbles generated at the surface of the catalysts during the HER test.

Based on the kinetic current, the activity of the catalyst can be determined. The mass activity or area specific activity at a certain potential can be directly obtained by dividing $i_{\mathrm{k}}$ by the catalyst mass or the electrochemical surface area (ECSA). The exchange current density $\left(i_{0}\right)$ is the forward or backward reaction rate at the equilibrium potential. It can be obtained by fitting $i_{\mathrm{k}} v s$. the overpotential $(\eta)$ using the Butler-Volmer equation, which is described by Equation (6):

$$
i_{\mathrm{k}}=i_{0}\left(e^{\frac{\alpha F}{R T} \eta}-e^{\frac{-(1-\alpha) F}{R T} \eta}\right) .
$$

Here, $\alpha$ is the charge transfer coefficient. The value of $i_{0}$ can also be obtained from the micro-polarization region, which is the region where only several millivolts deviate from the equilibrium potential. In this narrow region, the diffusional component is negligible and the kinetic current can be represented by the measured current. The Butler-Volmer equation can be expanded by Taylor's formula, and can be simplified to Equation (7):

$$
i=i_{0} \frac{\eta F}{R T} \text {. }
$$

Thus, $i_{0}$ can also be obtained from the slope of linear fitting in the micro-polarization region.

For catalysts with low activity, a measurable current can only be obtained at high overpotential. At such high overpotentials, the current from the backward reaction (negative part in Equation (6)) is negligible, and the Butler-Volmer equation can be simplified to the Tafel equation (Equation (8)):

$$
\eta=A \log \left(\frac{i_{\mathrm{k}}}{i_{0}}\right) .
$$

Here, $A$ is the Tafel slope. Thus, the exchange current density can be obtained from the intercept of the Tafel plot, which is a plot of the overpotential as a function of $\log \left(i_{\mathrm{k}}\right)$.

However, for some catalysts with ultra-high activity (e.g., Pt in acid environment), mass transport remains a problem, even when the RDE technique is used [14,15]. The polarization curve approaches the diffusional overpotential curve (described by Equation (4)); thus, the error in the calculation of $i_{\mathrm{k}}$ becomes non-negligible, and $i_{0}$ is often underestimated. In this case, further improvement of the mass transport is required for correct kinetic measurement. Fig. 2 summarizes the HOR/HER $i_{0}$ for Pt in acid obtained by different techniques. The $i_{0}$ obtained by the RDE method is around $1 \mathrm{~mA} \mathrm{~cm} \mathrm{Pt}^{-2}$, which is significantly underestimated. Other techniques, such as scanning electrochemical microscopy (SECM), floating electrodes, and the hydrogen pump in a fuel cell setup, have been used for the measurement of ultra-fast kinetics. With these techniques, the mass transport of $\mathrm{H}_{2}$ is improved and much higher $i_{0}$ values (20-80 $\mathrm{mA} \mathrm{cm}_{\mathrm{Pt}}{ }^{-2}$ at room temperature) have been obtained. For example, in the hydrogen pump setup with a fuel cell configuration, the liquid electrolyte is absent so that the hydrogen gas diffuses directly to the catalyst surface. Thus, the issue of low hydrogen solubility in the liquid electrolyte is precluded.

\section{MECHANISM OF THE CATALYTIC PROCESS}

A catalyst is always needed to accelerate the reaction. For real application, heterogeneous catalysts are generally employed for the HOR/HER. The adsorption and desorption of the reactants and products are associated with the heterogeneous catalytic process. There are three generally accepted elementary steps: Tafel, Heyrovsky, and Volmer (Equations (9-11)).

Tafel:

$$
\mathrm{H}_{2}+2 * \leftrightarrow 2 \mathrm{H}_{\mathrm{ad}}
$$

Heyrovsky:

$$
\mathrm{H}_{2}+* \leftrightarrow \mathrm{H}_{\mathrm{ad}}+\mathrm{H}^{+}+\mathrm{e}^{-}
$$




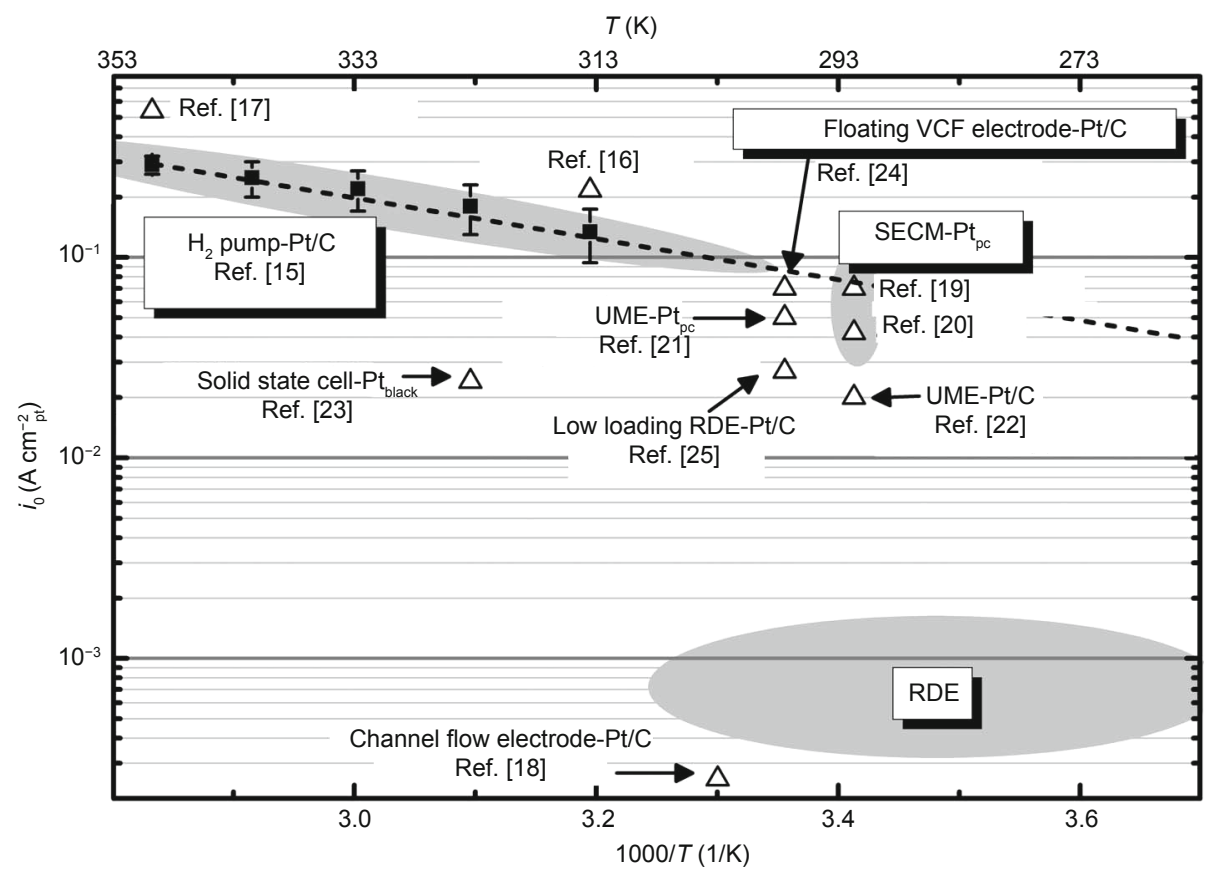

Figure 2 HOR/HER $i_{0}$ values measured using Pt electrodes with various techniques: RDE, $\mathrm{H}_{2}$ pump [15-17], channel flow electrode [18], SECM [19, 20], ultramicroelectrode [21,22], solid state cell [23], floating vaccum filtered catalyst electrode [24], low loading RDE [25]. Reprinted with permission from Ref. [15] (Copyright 2015, the Electrochemical Society).

Volmer:

$$
\mathrm{H}_{\mathrm{ad}} \leftrightarrow \mathrm{H}^{+}+\mathrm{e}^{-}+*
$$

Here, * denotes the hydrogen adsorption sites of the catalysts, and $\mathrm{H}_{\mathrm{ad}}$ is the adsorbed hydrogen. The Tafel reaction (Equation (9)) is the adsorption of $\mathrm{H}_{2}$ without electron transfer. The Heyrovsky reaction (Equation (10)) is the adsorption of $\mathrm{H}_{2}$ with simultaneous transfer of one proton and one electron, and generation of one adsorbed hydrogen unit. The Volmer reaction (Equation (11)) is the discharge of the adsorbed hydrogen unit and release of a proton. Therefore, the reaction may proceed by either the Tafel-Volmer or the Heyrovsky-Volmer mechanism.

The electrochemical rate equations for each step are shown in Table 1. The current density depends on the overpotential. The Tafel slope is used to describe the potential required to increase the current density ten-fold. For the reaction in which the Heyrovsky or Volmer step is the reaction step, the Tafel slope is $2 F / R T\left(120 \mathrm{mV} \mathrm{dec}^{-1}\right)$. When the Tafel reaction is the rate determining step, the Tafel slope is $F / 2 R T\left(30 \mathrm{mV} \mathrm{dec}^{-1}\right)$ [26]. Thus, it is possible to identify the reaction mechanism of the Tafel step from the Tafel slope. However, the Tafel slopes for the Heyrovsky and Volmer steps are the same, so it is impossible to differentiate them from the electrochemical polarization curve and another technique is required.

In base, the Heyrovsky and Volmer steps are revised to: Heyrovsky:

$$
\mathrm{H}_{2}+\mathrm{OH}^{-}+* \rightarrow \mathrm{H}_{\mathrm{ad}}+\mathrm{H}_{2} \mathrm{O}+\mathrm{e}^{-},
$$

Volmer:

$$
\mathrm{H}_{\mathrm{ad}}+\mathrm{OH}^{-} \rightarrow \mathrm{H}_{2} \mathrm{O}+\mathrm{e}^{-}+*
$$

Mathematically, this can be understood as simply add-

Table 1 Rate equations for each HOR/HER elemental step as the rate determining step

\begin{tabular}{cc}
\hline Rate determine step & Rate equation* \\
\hline Tafel & $r_{\mathrm{T}}=k_{1}\left[\left(\frac{1-\theta}{1-\theta^{0}}\right)^{2}\left(\frac{P_{\mathrm{H}_{2}}^{\mathrm{s}}}{P_{\mathrm{H}_{2}}^{\mathrm{e}}}\right)-\left(\frac{\theta}{\theta^{0}}\right)^{2}\right]$ \\
Heyrovsky & $r_{\mathrm{H}}=k_{2}\left[\left(\frac{1-\theta}{1-\theta^{0}}\right)\left(\frac{P_{\mathrm{H}_{2}}^{\mathrm{s}}}{P_{\mathrm{H}_{2}}^{\mathrm{e}}}\right) e^{\frac{\alpha F \eta}{R T}}-\left(\frac{\theta}{\theta^{0}}\right) e^{\frac{-(1-\alpha) F \eta}{R T}}\right]$ \\
Volmer & $r_{\mathrm{V}}=k_{3}\left[\left(\frac{\theta}{\theta^{0}}\right) e^{\frac{\alpha F \eta}{R T}}-\left(\frac{1-\theta}{1-\theta^{0}}\right) e^{\frac{-(1-\alpha) F \eta}{R T}}\right]$
\end{tabular}

* $P_{\mathrm{H}_{2}}^{\mathrm{s}}$ is the concentration of the $\mathrm{H}_{2}$ at the electrode surface; $P_{\mathrm{H}_{2}}^{\mathrm{e}}$ is the concentration of the $\mathrm{H}_{2}$ in the electrolyte; $\theta^{0}$ is the surface coverage at the equilibrium potential. 
ing $\mathrm{OH}^{-}$to both sides of the equations. Durst et al. [16] suggested that the same processes occur on the surface of the catalyst in base as in acid, followed by rapid combination of $\mathrm{H}^{+}$and $\mathrm{OH}^{-}$given that $\mathrm{OH}^{-}$is abundant in alkaline electrolyte. Strmcnik et al. [27] proposed that $\mathrm{OH}^{-}$is first adsorbed on the catalyst surface to generate adsorbed $\mathrm{OH}\left(\mathrm{OH}_{\mathrm{ad}}\right)$. Subsequently, $\mathrm{H}_{\mathrm{ad}}$ and $\mathrm{OH}_{\mathrm{ad}}$ combine on the surface of the catalyst. According to Markovic's theory, enhancing $\mathrm{OH}^{-}$adsorption would be beneficial for the HOR/ HER kinetics. It is still challenging to perform in situ investigation of the reaction process at the molecular level. The details of adsorption and desorption at the catalyst surface are still not clear.

\section{ACTIVITY DESCRIPTORS}

Several descriptors have been proposed for estimation of the catalyst activity. The HOR/HER occurs on the surface of the heterogeneous catalysts. The binding energy of hydrogen on the surface of catalysts, which can also be expressed as the energy of formation of the metal hydride, has been used as a descriptor of the catalyst activity. The typical volcano curve for the HER was first drawn by Trasatti (Fig. 3a) [28]. The measured exchange currents were plotted as a function of the metal-hydride bond strength on a series of metals. The exchange current of the optimal metal catalyst for the HER was located near the peak of the volcano curve. This can be explained by the Sabatier principle which states that a splendid catalyst should have moderate binding ability. Therefore, this curve is also called Sabatier volcano. With the development of density functional theory (DFT) calculations, the HER exchange current density has been correlated with the calculated hydrogen binding energy (HBE) on the metal surface. Norskov and co-authors [29] plotted the measured HER activity in acid $v s$. the calculated binding energies, and a good volcano shape was demonstrated (Fig. 3b). The PGMs (Pt, Pd, Ir, Rh) correspond to the peak of the plots, where these metals exhibit the highest HOR/HER activity. Ni, Co, Mo, etc., correspond to the left branch of the plot, where these metals have a stronger hydrogen binding energy than the optimal value. $\mathrm{Cu}, \mathrm{Ag}$, and
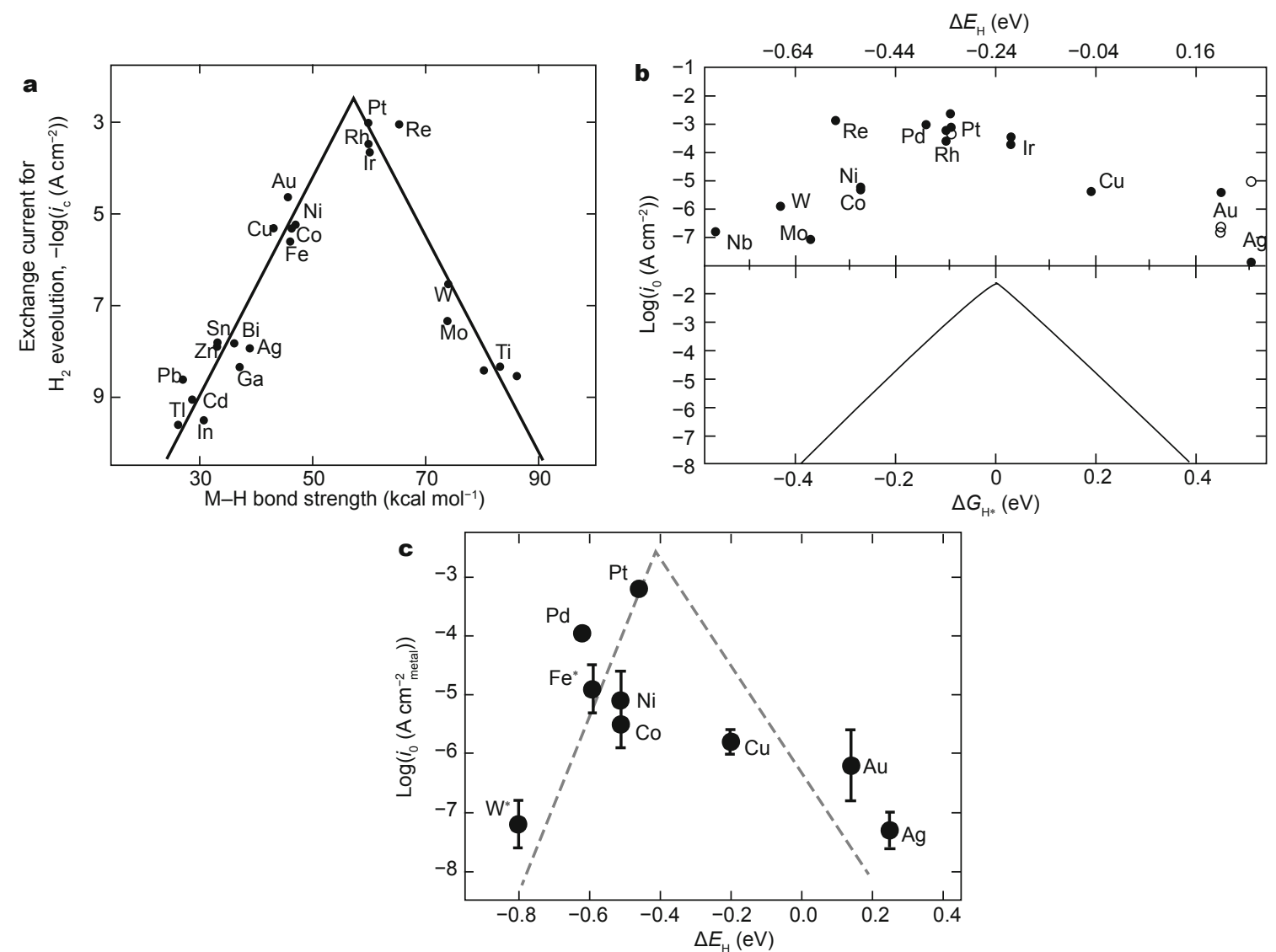

Figure 3 (a) Exchange current density for HER in acid, plotted as a function of the strength of intermediate metal-hydrogen bond formed during electrochemical reaction itself. (b) Exchange current density for HER in acid, plotted as a function of the calculated hydrogen chemisorption energy per atom. (c) Exchange current density for HER in base, plotted as a function of the calculated hydrogen binding energy. Reprinted with permission from Ref. [28-30] (Copyright 1972, Elsevier; 2005, the Electrochemical Society; and 2013, the Royal Society of Chemistry, respectively). 
Au correspond to the right branch, where the interaction with these metals is too weak for adsorption of the reactants. Yan and co-authors [30] demonstrated that the hydrogen binding energy can also be used as a descriptor for the HER activity measured in base, where a similar volcano shaped plot was also obtained (Fig. 3c). By using the calculated hydrogen binding energy, the plot allows prediction of the HOR/HER activity for efficient screening of highly active HOR/HER catalysts.

Some other descriptors have also been proposed for the HOR/HER. Bard and co-authors [31] used a pattern recognition method to determine the best correlation to the HOR/HER activity. The HER exchange current density was plotted based on 50 materials properties for 38 elements. It was found that the melting points and bulk modulus exhibited a meaningful correlation to the HER exchange current density. The exchange current density followed a monotonic trend with increasing bulk modulus. Surprisingly, the relationship between the exchange current density and the melting point was also volcano-type, and the melting points of the elements with the highest reaction activity were located within the optimum range of $1800-2750 \mathrm{~K}$. This melting point correlation is even better than the d-band centers, which is another parameter representing the hydrogen binding energy. These attempts provide additional avenues to predict highly active HOR/HER catalysts. However, the understanding of the relationship between the activity and the properties is still insufficient.

\section{ACTIVITY IN ACID VS. BASE}

It was found that the $\mathrm{pH}$ of the electrolyte is also an important factor that influences the activity of the catalyst. The HOR/HER activities for the same catalyst are different in acid and base. Sheng and co-authors [14] found that the HOR/HER activity is more than two orders of magnitude lower for the reaction catalyzed by $\mathrm{Pt}$ in base than in acid (Fig. 4). Durst and co-authors [32] further confirmed a difference in the catalyst activity in acid and base for other PGMs, such as Ir and Pd. The HOR/HER activity of Pt is very high in acid; thus, a very small amount of Pt is sufficient to accelerate the reaction and achieve an adequate current density. However, due to its low activity in base, much more $\mathrm{Pt}$ is required under basic conditions, such as in alkaline fuel cells or anion exchange membrane fuel cells. The reason for the lower activity in base is still not clear, but certain reports have provided some insight into this matter. The hydrogen binding energy is conventionally measured by the vacuum technique or calculated by the DFT method. However, the influences of the electrolyte are excluded by these approaches. Yan and co-authors [33] deduced that
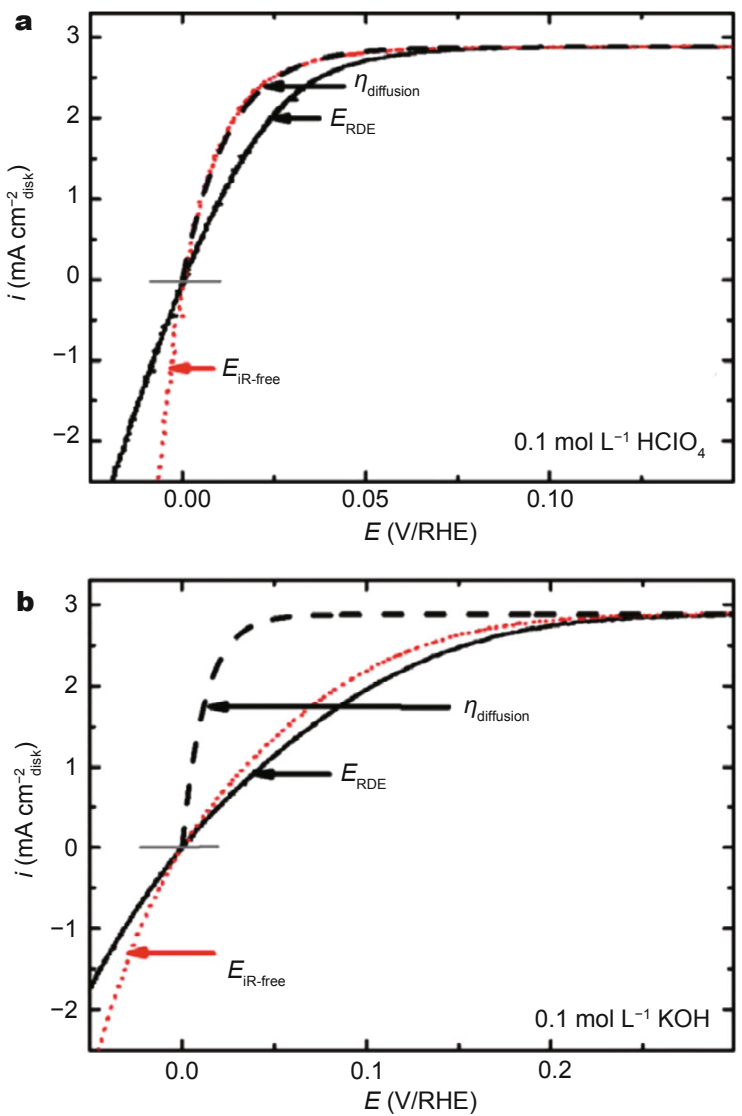

Figure 4 Polarization curve for HOR/HER on polycrystalline Pt disk in (a) $0.1 \mathrm{~mol} \mathrm{~L}^{-1} \mathrm{HClO}_{4}$ and (b) $0.1 \mathrm{~mol} \mathrm{~L}^{-1} \mathrm{KOH}$ at $1600 \mathrm{rpm}$. The solid black lines are the measured curves, and the dotted red lines are the curves after $i \mathrm{R}$ correction. The dashed black lines are the Nernstian diffusion overpotential calculated according to Equation (4). Reprinted with permission from Ref. [14] (Copyright 2010, the Electrochemical Society).

the underpotentially deposited hydrogen $\left(\mathrm{H}_{\text {upd }}\right)$ peaks for Pt were related to the hydrogen binding energy; thus, the true hydrogen binding energy for $\mathrm{Pt}$ at a particular $\mathrm{pH}$ can be measured from the $\mathrm{H}_{\text {upd }}$. The hydrogen binding energy was found to be $\mathrm{pH}$ dependent, and the hydrogen binding energy of Pt became stronger at higher $\mathrm{pH}$. The HOR activity of $\mathrm{Pt}$ over a wide $\mathrm{pH}$ range of the electrolyte (from 0 to 13) was also measured in buffer solution, demonstrating that the activity decreased with increasing $\mathrm{pH}$. A linear relationship between the binding energy and the HOR activity was found. In other words, as the $\mathrm{pH}$ increases, the binding energy of Pt increases; thus, the HOR activity decreases. DFT calculations show that the hydrogen binding energy of Pt is still slightly higher than the ideal value; thus, a further increase of the hydrogen binding energy results in lower HOR/HER activity. This is consistent with the increased measured hydrogen binding energy of Pt at high 
$\mathrm{pH}$. Such $\mathrm{pH}$ dependence of the relationship between the binding energy and the HOR activity is universal. In a later study, Yan and co-authors [34] showed that this relationship also holds for Ir, Pd, and Rh, and a universal slope is also found. However, the detailed mechanism of how the electrolyte changes the binding energy of the catalyst is still unknown.

\section{RECENT ADVANCES IN HOR/HER CATALYSTS}

In the volcano-shaped plot of the HOR/HER activity, the PGMs (Pt, Ir, Pd, etc.,) correspond to the optimal hydrogen binding energy region, and exhibit the highest activity. However, the high price of these PGMs hinders their application. As a benefit of the recent advancement in nanotechnology, certain catalysts with higher activities or low price (i.e., non-precious metals) have been developed to lower the amount of PGMs used in electrolyzers and fuel cells. The newly developed HOR/HER catalysts are discussed below.

\section{PGM-free HER catalysts active in acid}

Due to the ultra-high activity of PGMs in acid, a very small amount of the catalyst is adequate for use. Therefore, researchers are not interested in modifying these PGM catalysts to further reduce the catalyst loading. A more attractive field is to develop non-precious metal catalysts to avoid the use of any costly PGMs. Unfortunately, very few PGM-free HOR catalysts that are functional in acid have been reported. However, several PGM-free HER catalysts have been reported with impressive activities [35]. Table 2 summarizes the recently published PGM-free HER catalysts, including metal chalcogenides, phosphides, nitrides, brides, carbides, and hybrid materials. The HER performance of $\mathrm{Pt}$ is also listed in Table 2 for comparison. Note that due to the ultrafast HOR/HER kinetics of Pt in acid, the overpotential at $10 \mathrm{~mA} \mathrm{~cm}$ cm $^{-2}$ only comes from mass transport (Equation (4)) and is not related to the kinetics of the catalyst [36].

\section{$\mathrm{MoS}_{2}$}

One very important factor for catalysts to serve as PGMfree HER catalysts in acidic environment is the stability. Most PGM-free compounds are unstable in acid; thus, it is impossible to use them as catalysts under acidic conditions. Unlike most of the non-precious metals, Mo is stable under acidic conditions. Mo itself is not active for the HER. A NiMo alloy was found to be highly active in acid, but was not stable [84]. Recent research has focused on molybdenum compounds that are stable in acid. These have been found to be good candidates for the HER.
In 2005, Norskov and co-authors [85] predicted that $\mathrm{MoS}_{2}$ would be a good HER catalyst based on DFT calculations. Although the $\mathrm{MoS}_{2}$ basal sites are inert to the HER, the $\mathrm{MoS}_{2}$ edge sites are active. Fig. 5 shows the structure of the $\mathrm{MoS}_{2}$ edge, which is similar to the active sites in the highly HER active enzyme, nitrogenase, which contains Fe and Mo. At the $\mathrm{MoS}_{2}$ edge, the sulfur atom, which binds to hydrogen, is 2-fold coordinated to Mo. The calculation results show that the first $\mathrm{H}$ bonds strongly to the edge, but when the $\mathrm{H}$ coverage is greater than 0.25 , the additional $\mathrm{H}$ atoms should be able to undergo adsorption on the edge with a lower barrier (a low overpotential of $\sim 0.1 \mathrm{~V}$ ), which is in favor of the HER. This suggests that nanometer-scale $\mathrm{MoS}_{2}$, which has more exposed edge sizes, would be a good HER catalyst. Nanosized $\mathrm{MoS}_{2}$ clusters on a graphite support were used to prepare a membrane electrode assembly that exhibits good HER performance.

Chorkendorff and co-authors [86] further experimentally confirmed that the edge sites of $\mathrm{MoS}_{2}$ are the active sites for HER rather than the basal sites. Triangular S-Mo-S trilayers were grown on an Au (111) substrate. For single trilayers, terrace sites on the basal plane and the edge sites at the particle edge were exposed. Two types of $\mathrm{MoS}_{2}$ were obtained under different annealing temperatures, resulting in different particle sizes (Figs $6 \mathrm{a}$ and $\mathrm{b}$ ). The exchange current densities for the HER were plotted vs. the $\mathrm{MoS}_{2}$ area coverage and $\mathrm{MoS}_{2}$ edge length, respectively (Figs 6c and d). It was found that the rate of reaction is directly proportional to the number of edge sites for all samples, regardless of the particle size. Thus, the edge sites were confirmed as the active sites.

To improve the HER performance of $\mathrm{MoS}_{2}$, Cui and co-authors [37] synthesized $\mathrm{MoS}_{2}$ films with vertically aligned layers, resulting in maximal exposure of the edges. The film was prepared by converting the Mo thin film into $\mathrm{MoS}_{2}$ through a rapid sulfurization process, which can also be adopted to prepare $\mathrm{MoSe}_{2}$ thin films. A high exchange current density $\left(2.2 \times 10^{-6} \mathrm{~A} \mathrm{~cm}^{-2}\right)$ was obtained given that all the surface sites were edge sites.

Although the edge sites were maximally exposed in the vertically aligned $\mathrm{MoS}_{2}$ layers, these were only 2D planes full of active sites. Some effort has been expended to make catalyst powders that can be used to make 3D catalyst layers with a larger number of exposed active sites. By increasing the surface area with a high distribution of $\mathrm{MoS}_{2}$ edge sites, the HER mass activity could be further improved. Jaramillo and co-authors [44] grew $\mathrm{MoS}_{2}$ shells with dimensions of $\sim 2-5 \mathrm{~nm}$ on vertically oriented substoichiometric $\mathrm{MoO}_{3}$ cores ( 20-50 $\mathrm{nm}$ in diameter). The substoichiometric $\mathrm{MoO}_{3}$ core has good conductivity, and the ultra-thin and 
Table 2 Summary of the PGM-free HER catalysts active in acid

\begin{tabular}{|c|c|c|c|c|c|c|}
\hline Catalyst & $\begin{array}{l}\text { Loading } \\
\left(\mathrm{mg} \mathrm{cm}^{-2}\right)\end{array}$ & $\begin{array}{l}\text { Current density } \\
\left(\mathrm{mA} \mathrm{cm}^{-2}\right)\end{array}$ & $\begin{array}{c}\text { Overpotential } \\
(\mathrm{mV})\end{array}$ & Electrolyte & Tafel slope $\left(\mathrm{mV} \operatorname{dec}^{-1}\right)$ & Ref. \\
\hline $\mathrm{Pt}$ & & 10 & $\sim 18^{\mathrm{a}}$ & $0.1 \mathrm{~mol} \mathrm{~L}^{-1} \mathrm{HClO}_{4}$ & 30 & {$[36]$} \\
\hline $\mathrm{MoS}_{2}$ & 0.0085 & 8 & $\sim 400$ & $0.5 \mathrm{~mol} \mathrm{~L}^{-1} \mathrm{H}_{2} \mathrm{SO}_{4}$ & $\sim 110$ & [37] \\
\hline $\mathrm{MoS}_{2}$ & & 10 & $\sim 280$ & $0.5 \mathrm{~mol} \mathrm{~L}^{-1} \mathrm{H}_{2} \mathrm{SO}_{4}$ & 50 & [38] \\
\hline $\mathrm{MoS}_{2}$ & & 10 & 187 & $0.5 \mathrm{~mol} \mathrm{~L}^{-1} \mathrm{H}_{2} \mathrm{SO}_{4}$ & 43 & [39] \\
\hline $\mathrm{MoS}_{2}$ & 0.285 & 10 & $\sim 180$ & $0.5 \mathrm{~mol} \mathrm{~L}^{-1} \mathrm{H}_{2} \mathrm{SO}_{4}$ & 55 & [40] \\
\hline $\mathrm{MoS}_{2}$ & & 10 & $\sim 200$ & $0.5 \mathrm{~mol} \mathrm{~L}^{-1} \mathrm{H}_{2} \mathrm{SO}_{4}$ & 40 & {$[41]$} \\
\hline $\mathrm{MoS}_{2}$ & 0.06 & 10 & $\sim 220$ & $0.5 \mathrm{~mol} \mathrm{~L}^{-1} \mathrm{H}_{2} \mathrm{SO}_{4}$ & 50 & {$[42]$} \\
\hline $\mathrm{MoS}_{2}$ & 0.28 & 10 & $\sim 150$ & $0.5 \mathrm{~mol} \mathrm{~L}^{-1} \mathrm{H}_{2} \mathrm{SO}_{4}$ & 41 & [43] \\
\hline $\mathrm{MoS}_{2}$ & & 10 & $\sim 250$ & $0.5 \mathrm{~mol} \mathrm{~L}^{-1} \mathrm{H}_{2} \mathrm{SO}_{4}$ & 50 & [44] \\
\hline $\mathrm{MoS}_{2}$ & 0.285 & 10 & $\sim 190$ & $0.5 \mathrm{~mol} \mathrm{~L}^{-1} \mathrm{H}_{2} \mathrm{SO}_{4}$ & 50 & [45] \\
\hline $\mathrm{MoS}_{2}$ & 0.12 & 10 & $\sim 225$ & $0.5 \mathrm{~mol} \mathrm{~L}^{-1} \mathrm{H}_{2} \mathrm{SO}_{4}$ & 51 & [46] \\
\hline $\mathrm{MoS}_{2}$ & 0.28 & 10 & 149 & $0.5 \mathrm{~mol} \mathrm{~L}^{-1} \mathrm{H}_{2} \mathrm{SO}_{4}$ & 49 & [47] \\
\hline $\mathrm{MoS}_{2}$ & 0.19 & 10 & $\sim 160$ & $0.5 \mathrm{~mol} \mathrm{~L}^{-1} \mathrm{H}_{2} \mathrm{SO}_{4}$ & 50 & {$[48]$} \\
\hline $\mathrm{MoS}_{2.7} @ \mathrm{NPG}^{\mathrm{b}}$ & $\sim 0.1$ & 10 & $\sim 215$ & $0.5 \mathrm{~mol} \mathrm{~L}^{-1} \mathrm{H}_{2} \mathrm{SO}_{4}$ & 41 & [49] \\
\hline $\mathrm{MoS}_{2}-\mathrm{Au}$ & 0.00103 & 10 & $\sim 220$ & $0.5 \mathrm{~mol} \mathrm{~L}^{-1} \mathrm{H}_{2} \mathrm{SO}_{4}$ & 69 & {$[50]$} \\
\hline $\mathrm{WS}_{2}$ & 0.35 & 10 & $\sim 170$ & $0.5 \mathrm{~mol} \mathrm{~L}^{-1} \mathrm{H}_{2} \mathrm{SO}_{4}$ & 48 & {$[51]$} \\
\hline $\mathrm{WS}_{2}$ & 0.4 & 10 & $\sim 270$ & $0.5 \mathrm{~mol} \mathrm{~L}^{-1} \mathrm{H}_{2} \mathrm{SO}_{4}$ & 58 & {$[52]$} \\
\hline $\mathrm{WS}_{2}$ & $0.0001-0.0002$ & 10 & $\sim 210$ & $0.5 \mathrm{~mol} \mathrm{~L}^{-1} \mathrm{H}_{2} \mathrm{SO}_{4}$ & 55 & [53] \\
\hline $\mathrm{WS}_{2} @ \mathrm{P}, \mathrm{N}, \mathrm{O}$-graphene & 0.113 & 10 & 125 & $0.5 \mathrm{~mol} \mathrm{~L}^{-1} \mathrm{H}_{2} \mathrm{SO}_{4}$ & 52.7 & [54] \\
\hline $\mathrm{FeS}_{2}$ & & 4 & $\sim 245$ & $0.5 \mathrm{~mol} \mathrm{~L}^{-1} \mathrm{H}_{2} \mathrm{SO}_{4}$ & 62.5 & {$[55]$} \\
\hline $\mathrm{NiS}_{2}$ & & 4 & $\sim 235$ & $0.5 \mathrm{~mol} \mathrm{~L}^{-1} \mathrm{H}_{2} \mathrm{SO}_{4}$ & 41.6 & \\
\hline $\mathrm{CoS}_{2}$ & & 4 & $\sim 220$ & $0.5 \mathrm{~mol} \mathrm{~L}^{-1} \mathrm{H}_{2} \mathrm{SO}_{4}$ & 44.6 & \\
\hline $\mathrm{Fe}_{0.43} \mathrm{Co}_{0.57} \mathrm{~S}_{2}$ & & 4 & $\sim 195$ & $0.5 \mathrm{~mol} \mathrm{~L}^{-1} \mathrm{H}_{2} \mathrm{SO}_{4}$ & 55.9 & \\
\hline $\mathrm{Ni}_{0.68} \mathrm{Co}_{0.32} \mathrm{~S}_{2}$ & & 4 & $\sim 275$ & $0.5 \mathrm{~mol} \mathrm{~L}^{-1} \mathrm{H}_{2} \mathrm{SO}_{4}$ & 66.9 & \\
\hline $\mathrm{FeSe}_{2}$ & & 4 & $\sim 270$ & $0.5 \mathrm{~mol} \mathrm{~L}^{-1} \mathrm{H}_{2} \mathrm{SO}_{4}$ & 65.3 & \\
\hline $\mathrm{NiSe}_{2}$ & & 4 & $\sim 217$ & $0.5 \mathrm{~mol} \mathrm{~L}^{-1} \mathrm{H}_{2} \mathrm{SO}_{4}$ & 56.9 & \\
\hline $\mathrm{CoSe}_{2}$ & & 4 & $\sim 200$ & $0.5 \mathrm{~mol} \mathrm{~L}^{-1} \mathrm{H}_{2} \mathrm{SO}_{4}$ & 42.4 & \\
\hline $\mathrm{Co}_{0.56} \mathrm{Ni}_{0.44} \mathrm{Se}_{2}$ & & 4 & $\sim 233$ & $0.5 \mathrm{~mol} \mathrm{~L}^{-1} \mathrm{H}_{2} \mathrm{SO}_{4}$ & 49.7 & \\
\hline $\mathrm{CoSe}_{2}$ & & 10 & 137 & $0.5 \mathrm{~mol} \mathrm{~L}^{-1} \mathrm{H}_{2} \mathrm{SO}_{4}$ & 40 & {$[56]$} \\
\hline $\mathrm{CoS}_{2}$ & & 10 & 147 & $0.5 \mathrm{~mol} \mathrm{~L}^{-1} \mathrm{H}_{2} \mathrm{SO}_{4}$ & 51.6 & {$[57]$} \\
\hline Iron-nickel sulfide (INS) & 0.254 & 10 & 105 & $0.5 \mathrm{~mol} \mathrm{~L}^{-1} \mathrm{H}_{2} \mathrm{SO}_{4}$ & 40 & {$[58]$} \\
\hline $\mathrm{Fe}_{0.9} \mathrm{Co}_{0.1} \mathrm{~S}_{2}$ & 7 & 10 & $\sim 100$ & $0.5 \mathrm{~mol} \mathrm{~L}^{-1} \mathrm{H}_{2} \mathrm{SO}_{4}$ & 46 & [59] \\
\hline $\mathrm{Ni}_{2} \mathrm{P}$ & 1 & 10 & $\sim 120$ & $0.5 \mathrm{~mol} \mathrm{~L}^{-1} \mathrm{H}_{2} \mathrm{SO}_{4}$ & $\sim 46$ & {$[60]$} \\
\hline $\mathrm{NiP}_{2}$ & & 10 & 135 & $0.5 \mathrm{~mol} \mathrm{~L}^{-1} \mathrm{H}_{2} \mathrm{SO}_{4}$ & 48 & [61] \\
\hline $\mathrm{NiP}_{1.93} \mathrm{Se}_{0.07}$ & & 10 & 102 & $0.5 \mathrm{~mol} \mathrm{~L}^{-1} \mathrm{H}_{2} \mathrm{SO}_{4}$ & 42 & \\
\hline $\mathrm{CoP}$ & 2 & 10 & $\sim 70$ & $0.5 \mathrm{~mol} \mathrm{~L}^{-1} \mathrm{H}_{2} \mathrm{SO}_{4}$ & 50 & {$[62]$} \\
\hline $\mathrm{CoP}$ & 0.28 & 10 & $\sim 105$ & $0.5 \mathrm{~mol} \mathrm{~L}^{-1} \mathrm{H}_{2} \mathrm{SO}_{4}$ & 46 & [63] \\
\hline $\mathrm{CoP}$ & 0.92 & 10 & 67 & $0.5 \mathrm{~mol} \mathrm{~L}^{-1} \mathrm{H}_{2} \mathrm{SO}_{4}$ & 51 & {$[64]$} \\
\hline $\mathrm{CoP} / \mathrm{CNT}$ & 0.285 & 10 & 122 & $0.5 \mathrm{~mol} \mathrm{~L}^{-1} \mathrm{H}_{2} \mathrm{SO}_{4}$ & 54 & [65] \\
\hline Co phosphide/phosphate & 0.1 & 10 & 150 & $0.5 \mathrm{~mol} \mathrm{~L}^{-1} \mathrm{H}_{2} \mathrm{SO}_{4}$ & $\sim 53$ & [66] \\
\hline $\mathrm{FeP}$ & 3.2 & 10 & 55 & $0.5 \mathrm{~mol} \mathrm{~L}^{-1} \mathrm{H}_{2} \mathrm{SO}_{4}$ & 38 & {$[67]$} \\
\hline $\mathrm{FeP}$ & & 10 & 88 & $0.5 \mathrm{~mol} \mathrm{~L}^{-1} \mathrm{H}_{2} \mathrm{SO}_{4}$ & 35.5 & [68] \\
\hline $\mathrm{MoP}$ & 0.86 & 10 & 140 & $0.5 \mathrm{~mol} \mathrm{~L}^{-1} \mathrm{H}_{2} \mathrm{SO}_{4}$ & 54 & [69] \\
\hline $\mathrm{MoP}$ & 0.36 & 10 & 125 & $0.5 \mathrm{~mol} \mathrm{~L}^{-1} \mathrm{H}_{2} \mathrm{SO}_{4}$ & 54 & {$[70]$} \\
\hline $\mathrm{MoP} \mid \mathrm{S}$ & 1 & 10 & 86 & $0.5 \mathrm{~mol} \mathrm{~L}^{-1} \mathrm{H}_{2} \mathrm{SO}_{4}$ & 50 & {$[71]$} \\
\hline $\mathrm{Cu}_{3} \mathrm{P}$ & 15.2 & 10 & 143 & $0.5 \mathrm{~mol} \mathrm{~L}^{-1} \mathrm{H}_{2} \mathrm{SO}_{4}$ & 67 & {$[72]$} \\
\hline $\operatorname{NiMoN}_{x}$ & 0.25 & 5 & $\sim 225$ & $0.1 \mathrm{~mol} \mathrm{~L}^{-1} \mathrm{HClO}_{4}$ & 35.9 & {$[73]$} \\
\hline $\mathrm{Co}_{0.6} \mathrm{Mo}_{1.4} \mathrm{~N}_{2}$ & 0.24 & 10 & 200 & $0.1 \mathrm{~mol} \mathrm{~L}^{-1} \mathrm{HClO}_{4}$ & & [74] \\
\hline $\mathrm{MoB}$ & 2.5 & 10 & $\sim 210$ & $1.0 \mathrm{~mol} \mathrm{~L}^{-1} \mathrm{H}_{2} \mathrm{SO}_{4}$ & 55 & [75] \\
\hline $\mathrm{Mo}_{2} \mathrm{C}$ & 1.4 & 10 & $\sim 210$ & $1.0 \mathrm{~mol} \mathrm{~L}^{-1} \mathrm{H}_{2} \mathrm{SO}_{4}$ & 56 & \\
\hline $\mathrm{Mo}_{2} \mathrm{C}$ & 0.21 & 10 & $\sim 130$ & $0.5 \mathrm{~mol} \mathrm{~L}^{-1} \mathrm{H}_{2} \mathrm{SO}_{4}$ & $\sim 53$ & {$[76]$} \\
\hline $\mathrm{Mo}_{2} \mathrm{C} / \mathrm{CNT}$ & 2 & 10 & 152 & $0.1 \mathrm{~mol} \mathrm{~L}^{-1} \mathrm{HClO}_{4}$ & 55.2 & {$[77]$} \\
\hline $\mathrm{W}^{4} \mathrm{MoC}^{\mathrm{c}}$ & 1.28 & 10 & $\sim 130$ & $0.5 \mathrm{~mol} \mathrm{~L}^{-1} \mathrm{H}_{2} \mathrm{SO}_{4}$ & 52 & [78] \\
\hline $\mathrm{MoO}_{2}-\mathrm{C}$ & 0.35 & 10 & 58 & $0.5 \mathrm{~mol} \mathrm{~L}^{-1} \mathrm{H}_{2} \mathrm{SO}_{4}$ & 46 & [79] \\
\hline $\mathrm{C}_{3} \mathrm{~N}_{4} @ \mathrm{NG}^{\mathrm{d}}$ & 0.1 & 10 & 240 & $0.5 \mathrm{~mol} \mathrm{~L}^{-1} \mathrm{H}_{2} \mathrm{SO}_{4}$ & 51.5 & {$[80]$} \\
\hline $\mathrm{Ni} / \mathrm{NiO} / \mathrm{CoSe}_{2}$ & 0.28 & 10 & $\sim 87$ & $0.5 \mathrm{~mol} \mathrm{~L}^{-1} \mathrm{H}_{2} \mathrm{SO}_{4}$ & 39 & [81] \\
\hline $\mathrm{Co}_{9} \mathrm{~S}_{8} @ \mathrm{MoS}_{2} / \mathrm{CNFs}^{\mathrm{e}}$ & $\sim 0.212$ & 10 & 190 & $0.5 \mathrm{~mol} \mathrm{~L}^{-1} \mathrm{H}_{2} \mathrm{SO}_{4}$ & 110 & [82] \\
\hline Co-C-N complex & & 10 & 138 & $0.5 \mathrm{~mol} \mathrm{~L}^{-1} \mathrm{H}_{2} \mathrm{SO}_{4}$ & 55 & [83] \\
\hline
\end{tabular}

a) Tested in a RDE set-up with a rotation speed of $2500 \mathrm{rpm}$; b) NPG, nanoporous gold; c) W4MoC, molybdenum carbide-tungsten carbide with a molar ratio of 4:1 (W:Mo); d) NG, N-graphene; e) CNFs, carbon nanofibers. 
a
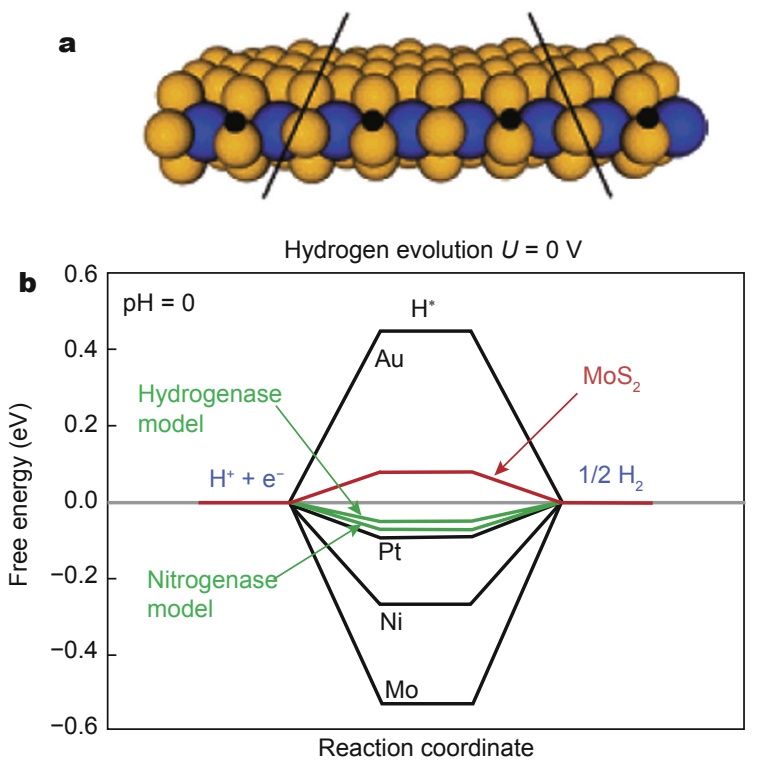

Figure 5 (a) Structural illustration of the $\mathrm{MoS}_{2}$ edge with $\mathrm{H}$ coverage of $50 \%$. Blue, yellow, and black spheres represent Mo, $\mathrm{S}$, and $\mathrm{H}$, respectively. (b) Calculated free energy diagram for hydrogen evolution at a potential of $U=0 \mathrm{~V}$ relative to the standard hydrogen electrode at $\mathrm{pH}=0$. Reprinted with permission from Ref. [85] (Copyright 2005, American Chemical Society).

a
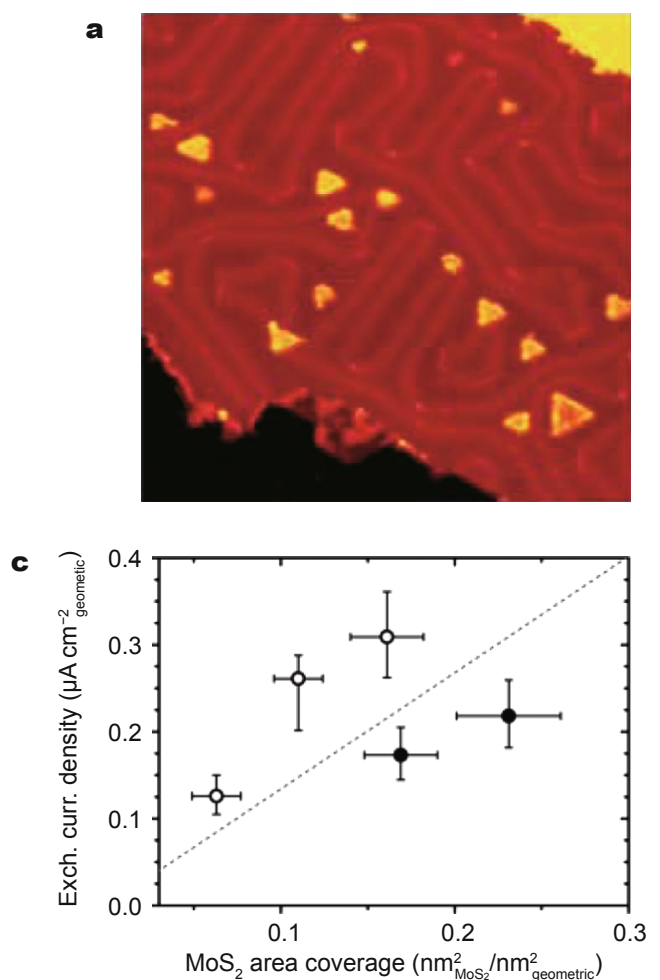

conformal $\mathrm{MoS}_{2}$ shell serves as both an HER catalyst and a protective layer. The $3 \mathrm{D}$ hierarchical structure results in high HER activity. Later, they used mesoporous silica as a template to tailor the surface structure of $\mathrm{MoS}_{2}$ to preferentially expose the edge sites [42]. The double-gyroid mesoporous silica template was prepared using $\mathrm{EO}_{19}-\mathrm{PO}_{43^{-}}$ $\mathrm{EO}_{19}$ surfactant, and the double-gyroid $\mathrm{MoS}_{2}$ structure was prepared by electrodeposition of Mo on the template followed by sulfidization with $\mathrm{H}_{2} \mathrm{~S}$. The obtained $\mathrm{MoS}_{2}$ has a highly ordered double-gyroid bicontinuous network with nanoscaled pores. The porous structure results in greater exposure of the $\mathrm{MoS}_{2}$ catalytically active edge sites, and an overpotential of $\sim 220 \mathrm{mV}$ is required to achieve a current density of $10 \mathrm{~mA} \mathrm{~cm}^{-2}$ with a catalyst loading of 0.06 $\mathrm{mg} \mathrm{cm}{ }^{-2}$.

Dai and co-authors [43] grew $\mathrm{MoS}_{2}$ nanoparticles on reduced graphene oxide $\left(\mathrm{MoS}_{2} / \mathrm{RGO}\right)$. The graphene sheet serves as a novel substrate for the nucleation and growth of $\mathrm{MoS}_{2}$ (Fig. 7a). Thus, the $\mathrm{MoS}_{2}$ nanoparticles selectively grew on graphene (Fig. 7b), with little free particle growth in the solution. The $\mathrm{MoS}_{2}$ nanoparticles are dimensionally small and lay flat on the graphene, with abundant open edges. Figs $7 \mathrm{c}$ and $\mathrm{d}$ summarize the electrochemical anal-

b
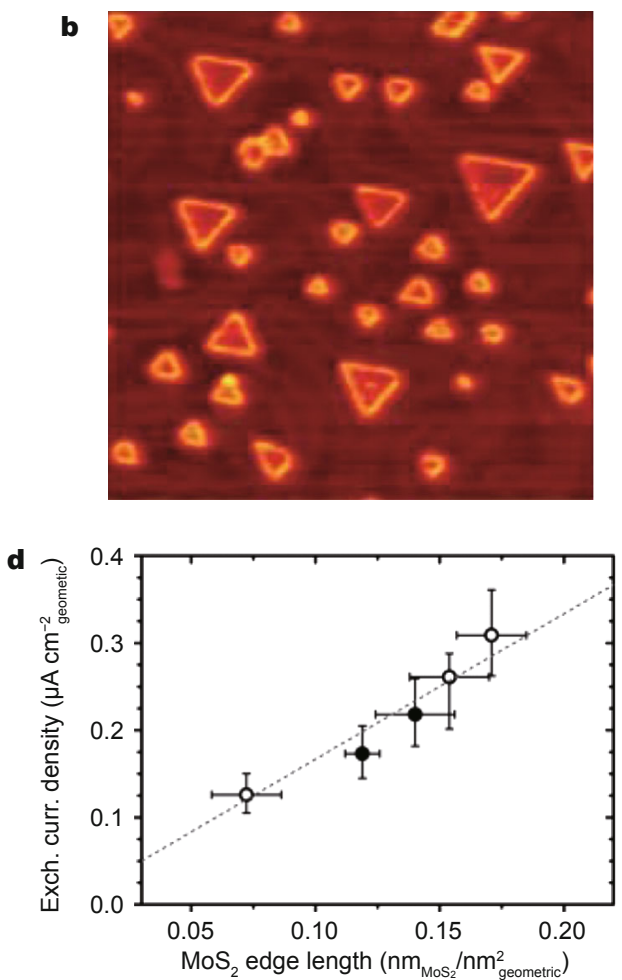

Figure 6 STM images of $\mathrm{MoS}_{2}$ nanoparticles on $\mathrm{Au}(111)$ with (a) low coverage and (b) high coverage. Exchange current density vs. MoS 2 area coverage (c) and $\mathrm{MoS}_{2}$ edge length (d). Open circles are the samples with low $\mathrm{MoS}_{2}$ coverage and filled circles are the samples with high MoS 2 coverage. Reprinted with permission from Ref. [86] (Copyright 2007, the American Association for the Advancement of Science). 


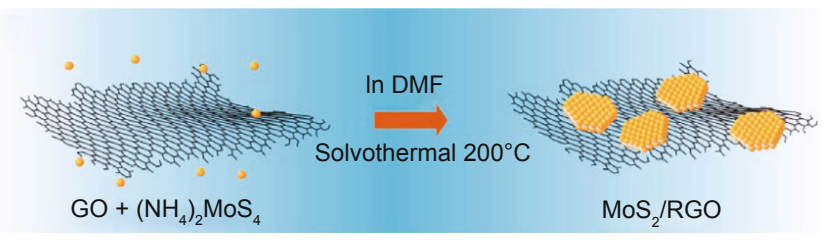

b

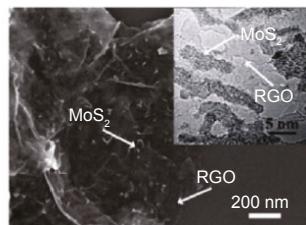

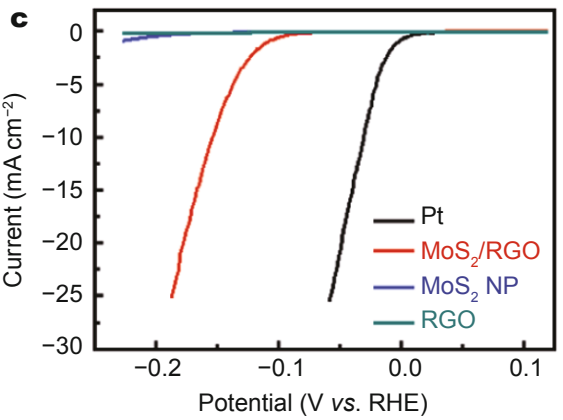

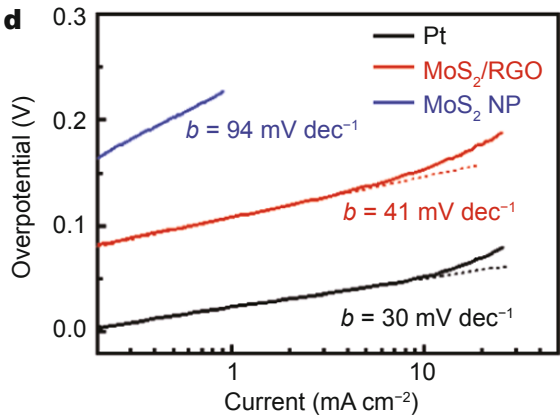

Figure 7 (a) Schematic solvothermal synthesis of $\mathrm{MoS}_{2} /$ RGO hybrid with GO sheets. (b) SEM and (inset) TEM images of the MoS $/$ RGO hybrid. (c) Polarization curves obtained with several catalysts with a catalyst loading of $0.28 \mathrm{mg} \mathrm{cm}^{-2}$. (d) Corresponding Tafel plots. Reprinted with permission from Ref. [43] (Copyright 2011, American Chemical Society).

ysis of the $\mathrm{MoS}_{2} / \mathrm{RGO}$. High HER activity is achieved with this hybrid catalyst, and an overpotential of $\sim 150 \mathrm{mV}$ is required to achieve a current density of $10 \mathrm{~mA} \mathrm{~cm}^{-2}$ with a catalyst loading of $0.28 \mathrm{mg} \mathrm{cm}^{-2}$.

Edge sites can also be obtained by introducing defects. Xie and co-authors [45] prepared defect-rich $\mathrm{MoS}_{2}$ ultra-thin nanosheets by using excessive thiourea in the synthesis. Thiourea can be adsorbed on the surface of nuclei, prohibiting the growth of large crystalline particles. Therefore, defect-rich $\mathrm{MoS}_{2}$ could be obtained, and the defects could serve as the HER active sites. This catalyst was found to be about 3 times as active as the defect-free congener.

Further efforts to improve the HER activity have involved modifying the structure of $\mathrm{MoS}_{2}$. Xie and co-authors [40] incorporated oxygen into $\mathrm{MoS}_{2}$. The oxygen-incorporated $\mathrm{MoS}_{2}$ has an enlarged interlayer spacing of 9.5 $\AA$, which is larger than that of the pristine $2 \mathrm{H}-\mathrm{MoS}_{2}(6.15$ $\AA$ ). Oxygen-incorporated $\mathrm{MoS}_{2}$ also has a disordered structure, which can offer more unsaturated sulfur atoms as the active sites for HER, as well as improve the conductivity. A large HER current density of $126.5 \mathrm{~mA} \mathrm{~cm}{ }^{-2}$ could be obtained at an overpotential of $300 \mathrm{mV}$ for this catalyst. Sun and co-authors [47] also produced $\mathrm{MoS}_{2}$ with an enlarged interlayer spacing of $9.4 \AA$ through a microwave-assisted strategy. An overpotential of $150 \mathrm{mV}$ is required to achieve an HER current density of $10 \mathrm{~mA} \mathrm{~cm}^{-2}$ with this catalyst at a loading of $0.28 \mathrm{mg} \mathrm{cm}^{-2}$. The electrical transport property is also an important factor that controls the catalyst performance. Jin and co-authors [39] prepared metallic nanosheets of $1 \mathrm{~T}-\mathrm{MoS}_{2}$ that exhibits significantly improved electrical conductivity. The $1 \mathrm{~T}-\mathrm{MoS}_{2}$ is chemically exfoliated from semiconducting $2 \mathrm{H}-\mathrm{MoS}_{2}$ via lithium intercalation. The $1 \mathrm{~T}-\mathrm{MoS}_{2}$ exhibits significantly improved HER performance relative to $2 \mathrm{H}-\mathrm{MoS}_{2}$ because $1 \mathrm{~T}-\mathrm{MoS}_{2}$ has metallic conductivity. A similar observation has also been reported by Chhowalla and co-authors [41].

Small molecules that mimic the active $\mathrm{MoS}_{2}$ edge sites also show HER activity. Chorkendorff and co-authors [87] showed that supported, incomplete cubane-type $\left[\mathrm{Mo}_{3} \mathrm{~S}_{4}\right]^{4+}$ clusters have very high per-molecule catalytic efficiency in the electrochemical HER. The cluster mimics the enzymatic active center of the $\mathrm{MoS}_{2}$ edge, which is the under-coordinated sulfur. However, this system is still limited by stability issues. Chang and co-authors [88] developed a $\mathrm{Mo}^{\mathrm{IV}}$-disulfide complex to mimic the $\mathrm{MoS}_{2}$ edge sites. The Mo atom is coordinated to a robust pentapyridyl ligand, as well as a $\mathrm{S}_{2}{ }^{2-}$ ligand. The $\mathrm{S}_{2}{ }^{2-}$ ligand structure provides a site similar to the disulfur-terminated $\mathrm{MoS}_{2}$ edge site. This catalyst can be used in acidic water, as well as in organic media.

In recent years, $\mathrm{MoS}_{2}$ has attracted much attention in the field of HER catalysts for use in acidic media. Since the edge sites are the active sites, intensive efforts have been focused on exposing more edge sites and avoiding exposure of the basal sites. By introducing nanostructures, the HER activity of $\mathrm{MoS}_{2}$ has been greatly improved compared with that of bulk $\mathrm{MoS}_{2}$. Further modification of the catalysts, such as incorporation of oxygen, can further improve the activity of $\mathrm{MoS}_{2}$. All of these features make $\mathrm{MoS}_{2}$ a good candidate for the fabrication of a low-cost electrolyzer. 


\section{$\mathrm{MS}_{2}$ and $\mathrm{MSe}_{2}(\mathrm{M}=\mathrm{Fe}, \mathrm{Co}, \mathrm{Ni})$}

In addition to $\mathrm{MoS}_{2}$, other transition metal disulfides have also been found to be HER active. The activity of $\mathrm{MoS}_{2}$ arises mainly from edge sulfur atoms that are 2-fold coordinated to Mo. In other transition metal dichalgogenides, similar under-coordinated sulfur atoms also exist. Thus, such compounds may also be HER active. Cui and co-authors [55] prepared first-row group VIII metal dichalcogenide $\left(\mathrm{MS}_{2}\right.$ and $\left.\mathrm{MSe}_{2}, \mathrm{M}=\mathrm{Fe}, \mathrm{Co}, \mathrm{Ni}\right)$ films through a facile process. A metal thin film was firstly prepared by e-beam evaporation, and was then converted to the corresponding metal dichalgogenides through a sulfurization/ selenization reaction. Fig. 8 summarizes the electrochemical analysis of the metal dichalcogenide films. All the metal dichalgogenides exhibit some HER activity, among which, $\mathrm{CoSe}_{2}$ exhibits the highest performance in the pristine dichalgogenides. They further fabricated $\mathrm{C} / \mathrm{CoSe}_{2}$ core/shell nanoparticles to get larger surface areas. At a loading of $\sim 37 \mu \mathrm{g} \mathrm{cm}^{-2}$, a very low overpotential $(90 \mathrm{mV})$ is required to achieve a current density of $4 \mathrm{~mA} \mathrm{~cm}^{-2}$ due to the high activity of $\mathrm{CoSe}_{2}$ and the enlarged surface areas. Later they grew $\mathrm{CoSe}_{2}$ nanoparticles on the carbon fiber paper through a two-step reaction: the growth of cobalt oxide nanoparticles on the carbon fiber paper followed by selenization [56]. Compared with the previously used e-beam method, this chemical method is more convenient and low cost. Due to the 3D structure of the carbon fiber paper, the catalyst has a very large roughness factor of about 640 and exhibits excellent HER activity. The overpotential required to achieve a current density of $10 \mathrm{~mA} \mathrm{~cm}^{-2}$ is only $147 \mathrm{mV}$. Similar to $\mathrm{CoSe}_{2}, \mathrm{CoS}_{2}$ is also a good HER catalyst. Jin and co-authors [57] prepared micro- and nano-structured metallic cobalt pyrite films. The surface area increases, and the microwire film has an enhanced bubble release rate, resulting in the highest HER performance.

Compared with single metal dichalgogenides, mixedmetal dichalgogenides with optimized compositions generally show better performance. Cui and co-authors [55] showed that $\mathrm{Fe}_{0.43} \mathrm{Co}_{0.57} \mathrm{~S}_{2}$ exhibited the best activity among first-row pristine and mixed dichalgogenides (Figs 8a and
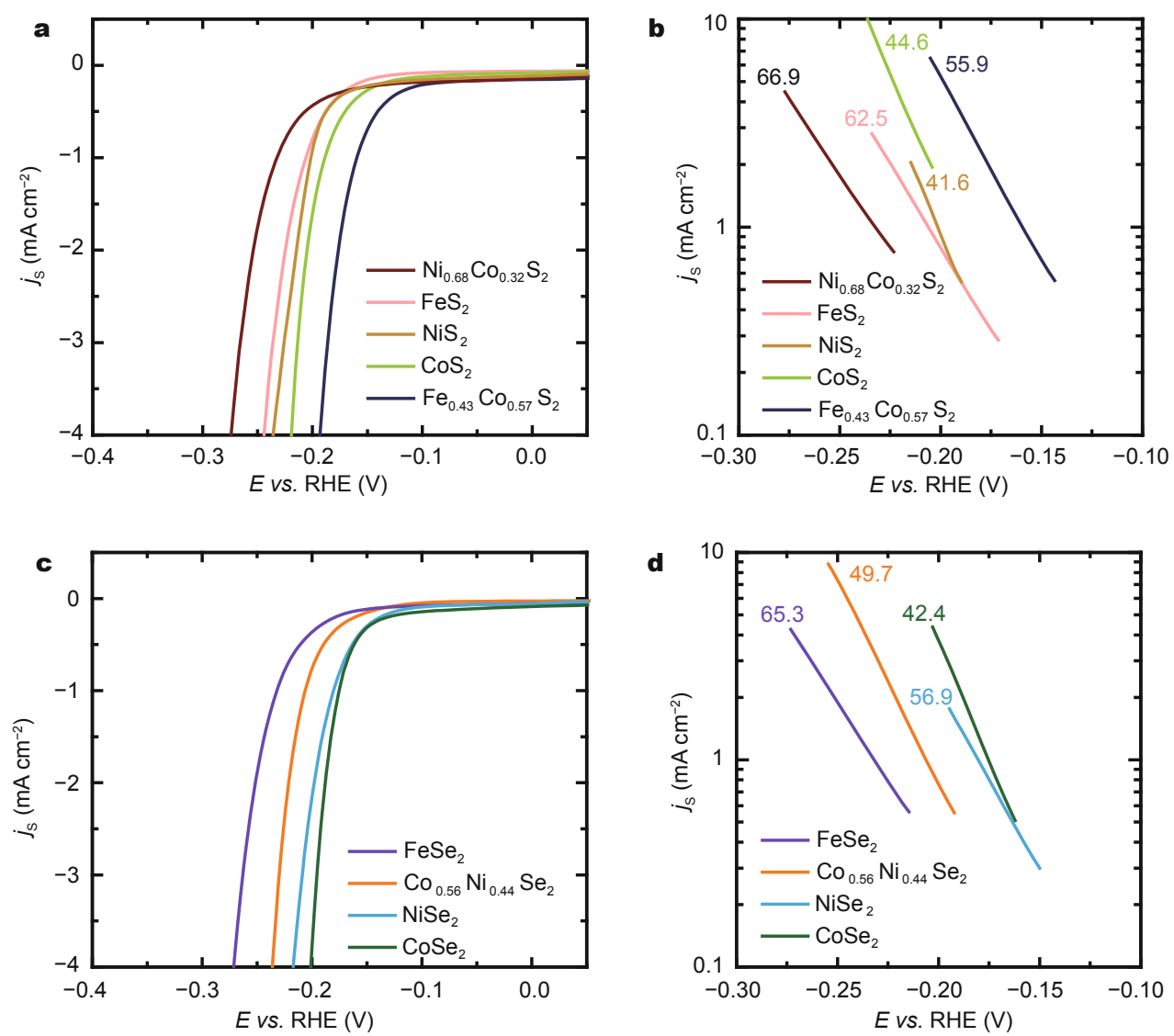

Figure 8 Electrochemical measurements of $\mathrm{MX}_{2}(\mathrm{M}=\mathrm{Fe}, \mathrm{Co}, \mathrm{Ni} ; \mathrm{X}=\mathrm{S}$ and $\mathrm{Se})$. (a) Polarization curves of $\mathrm{MS}_{2}$, in which the current density is normalized relative to the surface area. (b) Corresponding Tafel plots. (c) Polarization curves of $\mathrm{MSe}_{2}$, in which the current density is normalized relative to the surface area. (d) Corresponding Tafel plots. Reprinted with permission from Ref. [55] (Copyright 2013, the Royal Society of Chemistry). 
b). Dai and co-authors [59] studied a series of cobalt-doped $\mathrm{FeS}_{2}$ nanosheet-carbon nanotubes for the HER. Carbon nanotubes are introduced to enhance the electrical conductivity. $\mathrm{Fe}_{0.9} \mathrm{Co}_{0.1} \mathrm{~S}_{2}$ is found to have the highest HER activity with a low overpotential of $120 \mathrm{mV}\left(20 \mathrm{~mA} \mathrm{~cm}^{-2}\right.$ at a loading of $7 \mathrm{mg} \mathrm{cm}^{-2}$ ). DFT calculation showes that the energy barrier of Transition State 1 for hydrogen atom adsorption is lowered by doping $\mathrm{FeS}_{2}$ with cobalt. Yang and co-authors [58] synthesized ultra-thin nanosheets of metallic iron-nickel sulfide (INS) that had an even lower overpotential of $105 \mathrm{mV}$ at $10 \mathrm{~mA} \mathrm{~cm}{ }^{-2}$ at a loading of 0.254 $\mathrm{mg} \mathrm{cm}{ }^{-2} \cdot \alpha$-INS, which exhibits intrinsic metallic character, was synthesized by annealing $\beta$-INS. $\alpha$-INS exhibits higher activity due to the improved electrical conductivity.

\section{Phosphides}

Phosphides can also be used as HER catalysts in acidic environment. In 2005, Rodriguez and co-authors [89] projected that $\mathrm{Ni}_{2} \mathrm{P}(001)$ should have high activity as an HER catalyst due to the similarity of its structure to the [NiFe] hydrogenase based on DFT calculation (Fig. 9a). The Ni sites strongly adsorb hydrogen. When $\mathrm{Ni}$ is incorporated with $\mathrm{P}$, although the concentration of the Ni sites decrease, the $\mathrm{P}-\mathrm{Ni}$ bridge sites bond to the reaction intermediates with moderate strength, facilitating the HER. Fig. 9b shows the optimized structures for each step in the HER catalytic cycle. In 2013, Schaak and co-authors [60] synthesized $\mathrm{Ni}_{2} \mathrm{P}$ nanoparticles and experimentally confirmed their HER activity in acid. However, $\mathrm{Ni}_{2} \mathrm{P}$ is found to be unstable in alkaline solution. $\mathrm{Ni}_{2} \mathrm{P}$ nanoparticles were synthesized by a solution-based method with the assistance of trioctylphosphine (TOP) at $320^{\circ} \mathrm{C}$. The resulting particles are about $21 \mathrm{~nm}$ in size. At an overpotential of $130 \mathrm{mV}$, the $\mathrm{Ni}_{2} \mathrm{P}$ nanoparticles can catalyze the HER to produce a cur-

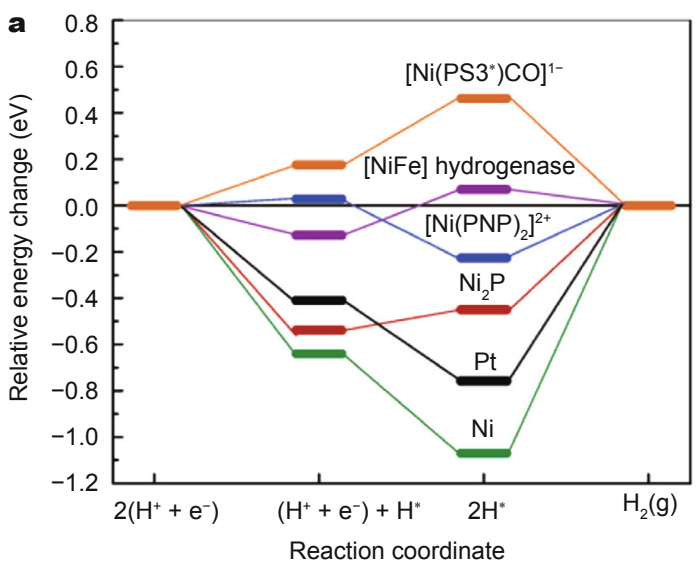

rent density of $20 \mathrm{~mA} \mathrm{~cm}^{-2}$ at a loading of $1 \mathrm{mg} \mathrm{cm}^{-2}$. Jin and co-authors [61] also reported that another nickel phosphide phase, $\mathrm{NiP}_{2}$, is also HER active in acid. The activity could be further improved by selenium doping, and an HER current density of $10 \mathrm{~mA} \mathrm{~cm}^{-2}$ could be achieved with $\mathrm{NiP}_{1.93} \mathrm{Se}_{0.07}$ at an overpotential of only $102 \mathrm{mV}$.

Several transition metal phosphides have also been reported as HER catalysts in acid. Schaak and co-authors [62] later synthesized CoP nanoparticles with a diameter of about $13 \mathrm{~nm}$ by a similar procedure used for $\mathrm{Ni}_{2} \mathrm{P}$ and found that these species exhibit even better HER performance. The overpotential required to achieve a current density of $20 \mathrm{~mA} \mathrm{~cm}^{-2}$ is reduced to $85 \mathrm{mV}$ at a catalyst loading of $3 \mathrm{mg} \mathrm{cm}^{-2}$. Sun and co-authors [65] decorated carbon nanotubes with $\mathrm{CoP}$ nanoparticles via low-temperature phosphidation of $\mathrm{Co}_{3} \mathrm{O}_{4} / \mathrm{CNT}$. The particle size is about $2-3 \mathrm{~nm}$. A current density of $10 \mathrm{~mA} \mathrm{~cm}^{-2}$ could be achieved with these nanoparticles at an overpotential of $122 \mathrm{mV}$ using a catalyst loading of $0.285 \mathrm{mg} \mathrm{cm}^{-2}$. They further synthesized nanoporous CoP nanowire arrays through phosphidation of the corresponding $\mathrm{Co}(\mathrm{OH}) \mathrm{F}$ precursor [64]. Higher HER performance was achieved due to the 3D structure. A similar 3D CoP nanostructure was also synthesized by Wang and co-authors [63]. The 3D urchin-like $\mathrm{CoP}$ nanoparticles with a diameter of $5 \mu \mathrm{m}$ were successfully prepared by phosphidation of $\mathrm{Co}\left(\mathrm{CO}_{3}\right)_{0.5}(\mathrm{OH}) \cdot 0.11 \mathrm{H}_{2} \mathrm{O}$, which was obtained by a hydrothermal reaction. Tour and co-authors [66] also reported that the porous Co phosphide/phosphate thin film (PCPTF) exhibits good HER activity in acid.

Inspired by the [FeFe] hydrogenases, Sun and co-authors [67] prepared FeP to serve as HER catalysts. The FeP nanowires were formed by conversion of $\mathrm{FeOOH}$ nanowires (Figs 10a and b). An overpotential of only $55 \mathrm{mV}$ is

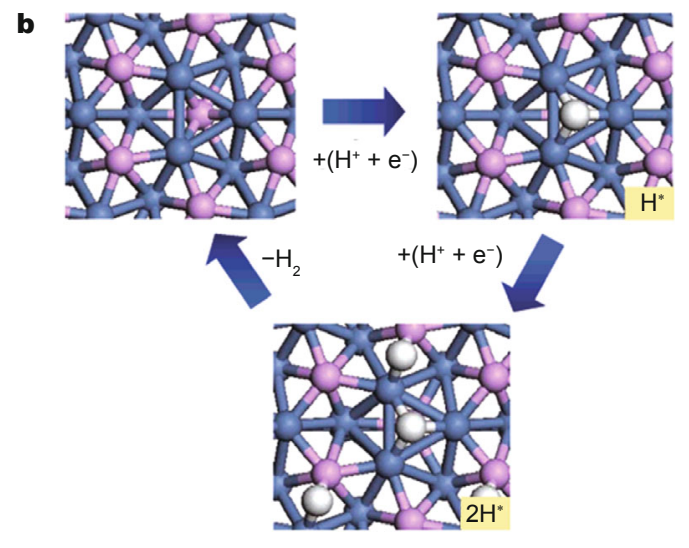

Figure 9 (a) Calculated energy changes for the HER. (b) Optimized structures for each step in the HER catalytic cycle on $\mathrm{Ni}_{2} \mathrm{P}(001)$ surface. Blue, purple, and white spheres represent Ni, P, and H, respectively. Reprinted with permission from Ref. [89] (Copyright 2005, American Chemical Society). 
a
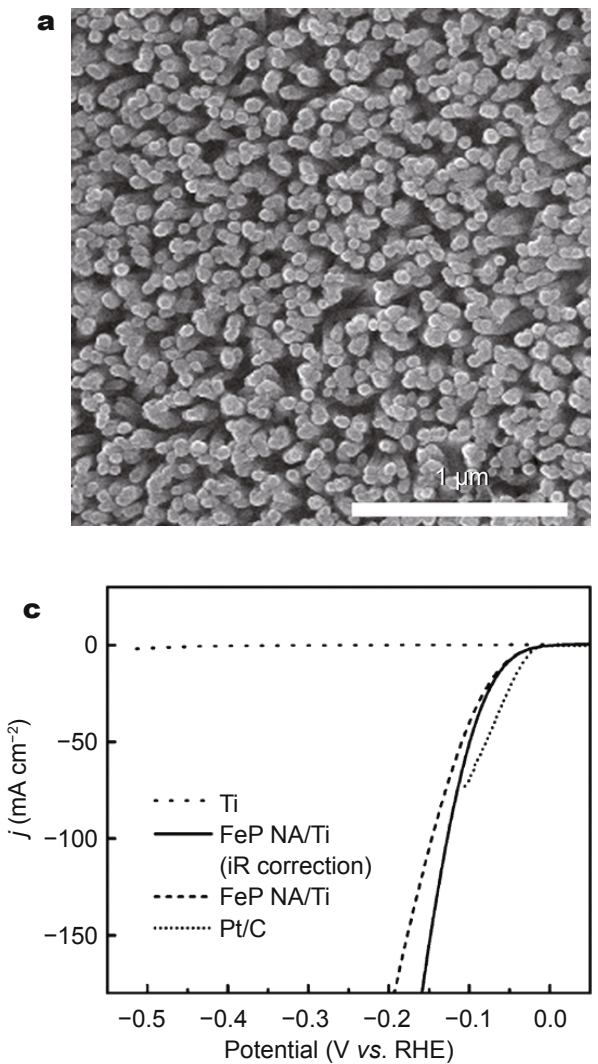

b

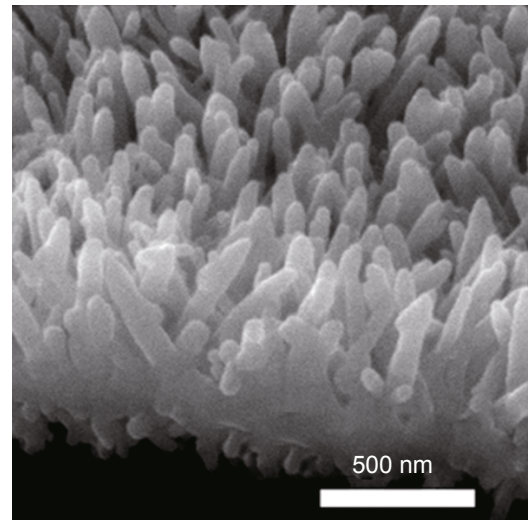

d

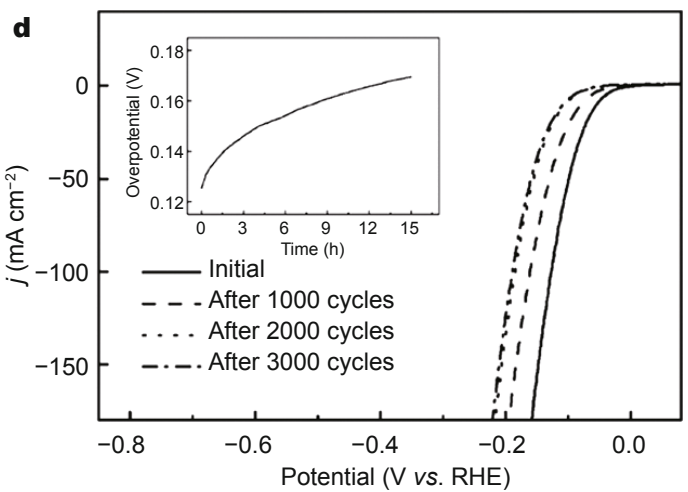

Figure 10 ( $\mathrm{a}$ and b) SEM images of the FeP nanowires. (c) Polarization curves of the FeP nanowires. (d) Durability test of the FeP nanowires. Reprinted with permission from Ref. [67] (Copyright 2014, WILEY-VCH Publisher, Inc.).

required to achieve a current density of $10 \mathrm{~mA} \mathrm{~cm}^{-2}$ at a loading of $3.2 \mathrm{mg} \mathrm{cm}^{-2}$ (Fig. 10c). However, this catalyst is not very stable in the durability test. In the test, a $45 \mathrm{mV}$ increase of the overpotential is observed after $15 \mathrm{~h}$ at a current density of $90 \mathrm{~mA} \mathrm{~cm}^{-2}$ (Fig. 10d). Wang and co-authors [68] synthesized FeP nanotube-based flexible electrodes by treating iron hydroxide nanotubes with phosphorus vapor. A current density of $10 \mathrm{~mA} \mathrm{~cm}{ }^{-2}$ could be achieved at an overpotential of $88 \mathrm{mV}$ and the catalyst is stable during a $14 \mathrm{~h}$ test.

MoP is also an HER catalyst. Wang and co-authors [69] synthesized $\mathrm{MoP}$ and $\mathrm{Mo}_{3} \mathrm{P}$. Compared with $\mathrm{Mo}$ and $\mathrm{Mo}_{3} \mathrm{P}$, MoP exhibits higher HER performance. DFT calculation indicates that the $\mathrm{P}$ atoms are the active sites, which is different from the case of $\mathrm{Ni}_{2} \mathrm{P}$ (Ni-P bridge sites are predicted to be the active sites). This result shows that $\mathrm{P}$ atoms play a role analogous to that of the $\mathrm{S}$ atoms in $\mathrm{MoS}_{2}$. MoP has the highest population of $\mathrm{P}$ sites, thus resulting in the highest HER performance. Sun and co-authors [70] also synthesized a closely interconnected network of MoP nanoparticles that display high HER activity. Jaramillo and co-authors [71] also prepared a MoP film (SEM analysis presented in Figs 11a and $\mathrm{b}$ ) that exhibits high HER performance. They further doped MoP with sulfur (MoP $\mid \mathrm{S})$ and obtained ultra-high HER activity. Figs 11c and d summarize the electrochemical analysis of the catalysts. An overpotential of only $64 \mathrm{mV}$ is required to achieve a current density of $10 \mathrm{~mA} \mathrm{~cm}^{-2}$ at a catalyst loading of $3 \mathrm{mg} \mathrm{cm}^{-2}$. The authors proposed that the HER performance of MoP|S can be further improved by introducing a high surface area catalyst structure.

Other phosphides, such as $\mathrm{Cu}_{3} \mathrm{P}$ [72], have also been found to be HER active. Based on the achievements in the recent three years, phosphides have become one of the most promising PGM-free HER catalysts for use in acidic conditions. An overpotential of less than $100 \mathrm{mV}$ is required to achieve a current density of $10 \mathrm{~mA} \mathrm{~cm}^{-2}$. This is close to the requirement for real applications.

\section{Other HER catalysts}

Certain other compounds, mainly associated with Mo, have been found to be HER active in acid. $\mathrm{NiMoN}_{x}$ [73], $\mathrm{MoB}$ [75], and $\mathrm{Mo}_{2} \mathrm{C}[76,77,90]$ have also been reported, where a current density of $10 \mathrm{mV} \mathrm{cm}^{-2}$ is achieved with 

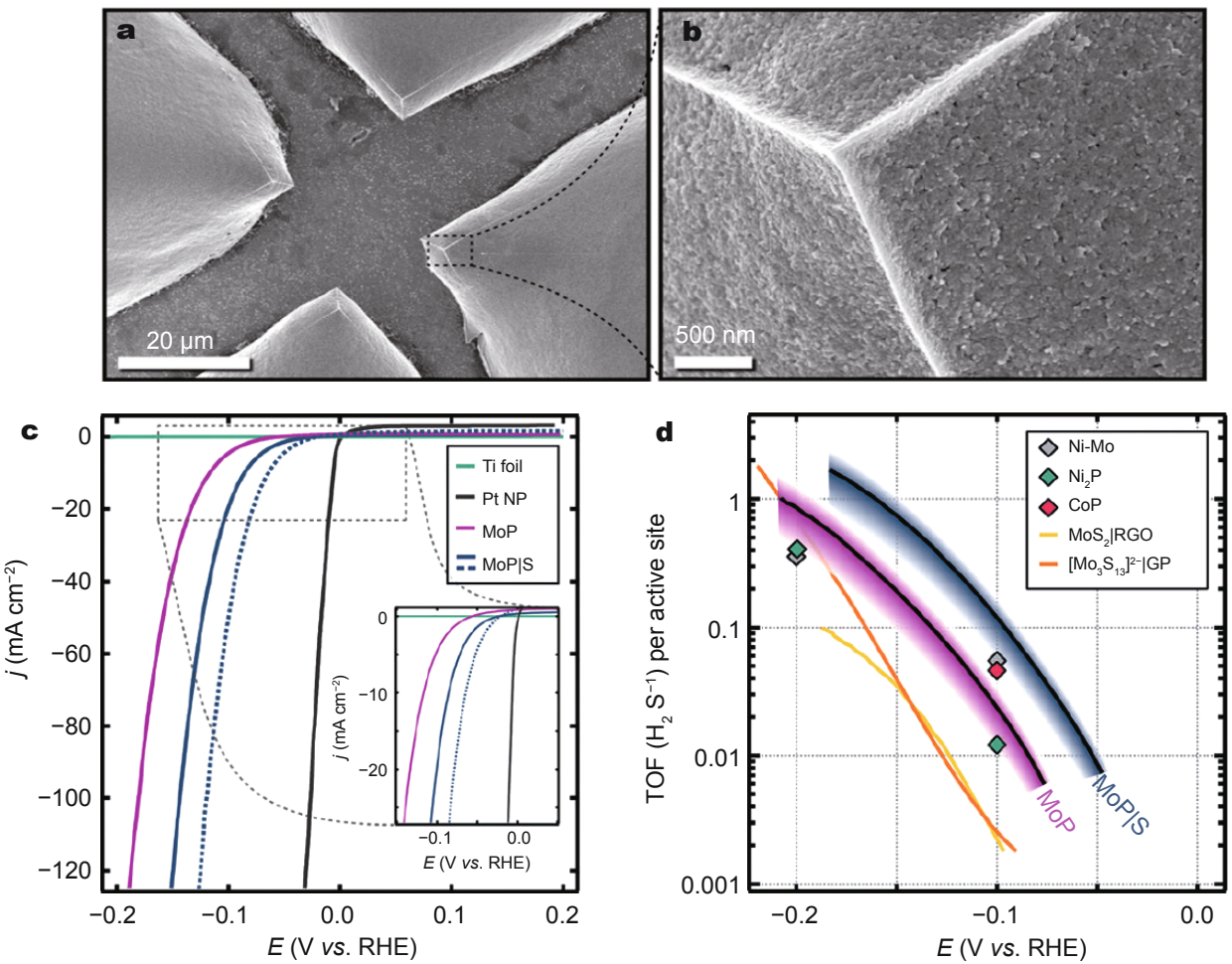

Figure 11 ( $\mathrm{a}$ and b) SEM images a MoP thin film on Ti foil. (c) Linear sweep voltammograms of MoP and MoP|S. The solid and dotted lines represent samples with a catalyst loading of approximately 1 and $3 \mathrm{mg} \mathrm{cm}^{-2}$, respectively. (d) TOF values of MoP and MoP $\mid \mathrm{S}$ together. Reprinted with permission from Ref. [71] (Copyright 2014, WILEY-VCH Publishier, Inc.).

an overpotential of around $200 \mathrm{mV}$. Hybrid catalysts, such as $\mathrm{Ni} / \mathrm{NiO} / \mathrm{CoSe}$ [81] and $\mathrm{MoS}_{2} / \mathrm{CoSe}$ [91], have also been found to exhibit superior HER activity relative to the single component catalysts.

Other than the inorganic catalysts, certain complexes obtained from high temperature pyrolysis also exhibit HER activity. Zhang and co-authors [83] obtained a Co-C-N complex via in situ carbonization of a cobalt ion-absorbed polyaniline (PANI) precursor. An overpotential of $138 \mathrm{mV}$ is required to achieve a current density of $10 \mathrm{~mA} \mathrm{~cm}^{-2}$. The active center is considered to be the $\mathrm{C}$ and $\mathrm{N}$ coordinated Co. A composite of the conducting polymer, poly(3,4-ethylenedioxythiophene) (PEDOT), and a non-conducting polymer, polyethylene glycol (PEG), is also found to be HER active in acid [92]. However, another group argued that the activity was derived from the substrate [93].

PGM-free catalysts that are functional in acid have attracted significant attention in recent years. Molybdenum compounds, including sulfides, nitrides, phosphides, borides, and carbides, have shown high activity in catalyzing the HER. Other transition metal sulfides and phosphides, such as $\mathrm{CoSe}_{2}$ and FeP, are also good HER catalysts in acid. To date, the PGM-free HER catalysts are still less ac- tive than Pt. To achieve a current density of $10 \mathrm{~mA} \mathrm{~cm}^{-2}$, an overpotential of more than $55 \mathrm{mV}$ is still needed for PGMfree catalysts. However, the low cost makes these catalysts competitive in real applications.

\section{HOR/HER catalysts in base}

In alkaline electrolyte, the HOR/HER activities of PGMs are generally lower than that in acidic electrolyte. Thus, there is still room to improve the HOR/HER activity of PGM catalysts in base. On the other hand, because of the lower activity of PGM catalysts in base, a larger amount of the catalysts is required to achieve the same performance as in acid. Therefore, it is more desirable to develop PGM-free catalysts as alternatives to PGM catalysts for use in base. Due to the less harsh conditions in base than in acid, more PGM-free catalysts can survive under basic environment. Certain nickel-based catalysts with impressive activity have been developed. More importantly, in contrast with the PGM-free catalysts in acidic conditions, under basic conditions, the PGM-free catalysts also demonstrate impressive HOR activity, which allows the fabrication of low cost PGM-free fuel cells. Table 3 summarizes recently developed catalysts for the HOR/HER in base. 
Table 3 Summary of the HOR/HER exchange current densities for the catalysts in base

\begin{tabular}{|c|c|c|c|c|}
\hline Catalyst & Electrolyte & Temperature $\left({ }^{\circ} \mathrm{C}\right)$ & Exchange current density $\left(\mathrm{mA} \mathrm{cm}_{\text {catalyst }}{ }^{-2}\right)$ & Ref. \\
\hline $\mathrm{Pt}(\mathrm{pc})^{\mathrm{a}}$ & $0.1 \mathrm{~mol} \mathrm{~L}^{-1} \mathrm{KOH}$ & 21 & 0.69 & {$[14]$} \\
\hline $\mathrm{Pt} / \mathrm{C}$ & $0.1 \mathrm{~mol} \mathrm{~L}^{-1} \mathrm{KOH}$ & 21 & 0.57 & \\
\hline $\mathrm{Pt} / \mathrm{C}$ & $0.1 \mathrm{~mol} \mathrm{~L}^{-1} \mathrm{NaOH}$ & 40 & 1.0 & {$[16]$} \\
\hline $\mathrm{Pd} / \mathrm{C}$ & $0.1 \mathrm{~mol} \mathrm{~L}^{-1} \mathrm{NaOH}$ & 40 & 0.06 & \\
\hline $\mathrm{Ir} / \mathrm{C}$ & $0.1 \mathrm{~mol} \mathrm{~L}^{-1} \mathrm{NaOH}$ & 40 & 0.37 & \\
\hline $\mathrm{Pt} / \mathrm{Cu} \mathrm{NW} \mathrm{N}^{\mathrm{b}}$ & $0.1 \mathrm{~mol} \mathrm{~L}^{-1} \mathrm{KOH}$ & r.t. ${ }^{c}$ & 2.0 & {$[94]$} \\
\hline $\mathrm{PtRu} / \mathrm{C}$ & $0.1 \mathrm{~mol} \mathrm{~L}^{-1} \mathrm{KOH}$ & r.t. & 0.7 & [95] \\
\hline $\mathrm{Pt} / \mathrm{C}$ & $0.1 \mathrm{~mol} \mathrm{~L}^{-1} \mathrm{KOH}$ & r.t. & 0.3 & \\
\hline $\mathrm{Ni}$ & $6 \mathrm{~mol} \mathrm{~L}^{-1} \mathrm{KOH}$ & 22 & 0.0004 & [96] \\
\hline $\mathrm{Ni}-\mathrm{Ti}$ & $6 \mathrm{~mol} \mathrm{~L}^{-1} \mathrm{KOH}$ & 22 & 0.003 & \\
\hline $\mathrm{Ni}$ & 30 wt.\% KOH & 25 & 0.0021 & [97] \\
\hline Ni-Mo & 30 wt.\% KOH & 25 & 0.026 & \\
\hline $\mathrm{Ni}-\mathrm{W}$ & 30 wt. $\% \mathrm{KOH}$ & 25 & 0.0065 & \\
\hline Co & 30 wt. $\% \mathrm{KOH}$ & 25 & 0.00094 & \\
\hline Co-Mo & 30 wt. $\% \mathrm{KOH}$ & 25 & 0.023 & \\
\hline $\mathrm{Co}-\mathrm{W}$ & 30 wt. $\% \mathrm{KOH}$ & 25 & 0.0012 & \\
\hline NiCoMo & $0.1 \mathrm{~mol} \mathrm{~L}^{-1} \mathrm{KOH}$ & r.t. & 0.015 & [98] \\
\hline $\mathrm{Ni} / \mathrm{N}-\mathrm{CNT}$ & $0.1 \mathrm{~mol} \mathrm{~L}^{-1} \mathrm{KOH}$ & r.t. & 0.028 & [99] \\
\hline $\mathrm{Ni}$ & $0.1 \mathrm{~mol} \mathrm{~L}^{-1} \mathrm{KOH}$ & r.t. & 0.0013 & \\
\hline
\end{tabular}

a) pc, polycrystalline disk; b) NW, nanowire; c) r.t., room temperature.

\section{PGM-based HOR/HER catalysts active in base}

Improvement of the HOR/HER of $\mathrm{Pt}$ in base has been achieved with certain approaches. A common method to improve the catalytic activity of Pt involves fabrication of Pt alloys or core/shell structures. When a foreign atom is introduced, the electronic state of $\mathrm{Pt}$ can be adjusted, and better adsorption of hydrogen can be achieved. The Pt alloys and core/shell structures have been studied intensively for the ORR and have been proved to exhibit enhanced catalytic performance [5]. It has been confirmed that this method can also be applied for enhancement of the HOR/ HER activity.

Yan and co-authors [94] synthesized Pt-coated $\mathrm{Cu}$ nanowires by partial galvanic displacement of $\mathrm{Cu}$ nanowires. Tuning by the $\mathrm{Cu}$ substrate results in the $\mathrm{Pt} / \mathrm{Cu}$ NWs having an exchange current density 3.5 times as high as that of pure Pt. Zhuang and co-authors [95] used PtRu alloys as HOR catalysts for the alkaline polymer electrolyte fuel cells. A peak power density of $1.0 \mathrm{~W} \mathrm{~cm}^{-2}$ is obtained, in comparison to $0.6 \mathrm{~W} \mathrm{~cm} \mathrm{~cm}^{-2}$ that is obtained when $\mathrm{Pt} / \mathrm{C}$ is used as the anode catalyst (Fig. 12a). The exchange current density on $\mathrm{PtRu} / \mathrm{C}$ is twice as high as that of $\mathrm{Pt} / \mathrm{C}$ in the RDE measurement (Fig. 12b). The enhanced HOR activity is attributed to the electronic effect of $\mathrm{Ru}$ on weakening the $\mathrm{Pt}-\mathrm{H}_{\mathrm{ad}}$ interaction, as revealed by the voltammetric behavior (Fig. 12c) and DFT calculations. Wang and co-authors
[100] also synthesized Pt/Ru core/shell nanoparticles to obtain enhanced HOR/HER activity. A 4-fold enhancement of the Pt mass activity is achieved by using single-crystalline Ru@Pt core-shell nanoparticles with two-monolayer-thick Pt shells. The authors believed that the improvement was derived from the lower optimal hydrogen binding energy of Ru@Pt.

Markovic and co-authors [101] believed that the adsorption of $\mathrm{OH}$ on the catalyst surface is also an important factor influencing the rate of the HOR/HER in base. They controllably arranged nanometer-scale $\mathrm{Ni}(\mathrm{OH})_{2}$ clusters on a platinum electrode surface. The HER activity is increased by a factor of 8 compared with that on the flat $\mathrm{Pt}$ (111) surface. The author attributed this increase to the bifunctional effect. The $\mathrm{Ni}(\mathrm{OH})_{2}$ edge promotes the dissociation of water. The released $\mathrm{OH}$ is adsorbed on the $\mathrm{Ni}(\mathrm{OH})_{2}$, and the released $\mathrm{H}$ is adsorbed on Pt. Subsequently, two $\mathrm{H}_{\mathrm{ad}}$ combine to release $\mathrm{H}_{2}$. The activity could be further improved by introducing $\mathrm{Li}^{+}$. A total increase in activity of ten-fold is obtained via $\mathrm{Li}^{+}$-induced destabilization of the $\mathrm{HO}-\mathrm{H}$ bonds. Subsequently, this $\mathrm{OH}$ enhancement behavior is further investigated for several catalysts [27].

\section{PGM-free HOR/HER catalysts active in base}

Due to the relatively mild conditions of the basic electrolyte, non-precious metals may exist stably under these condi- 

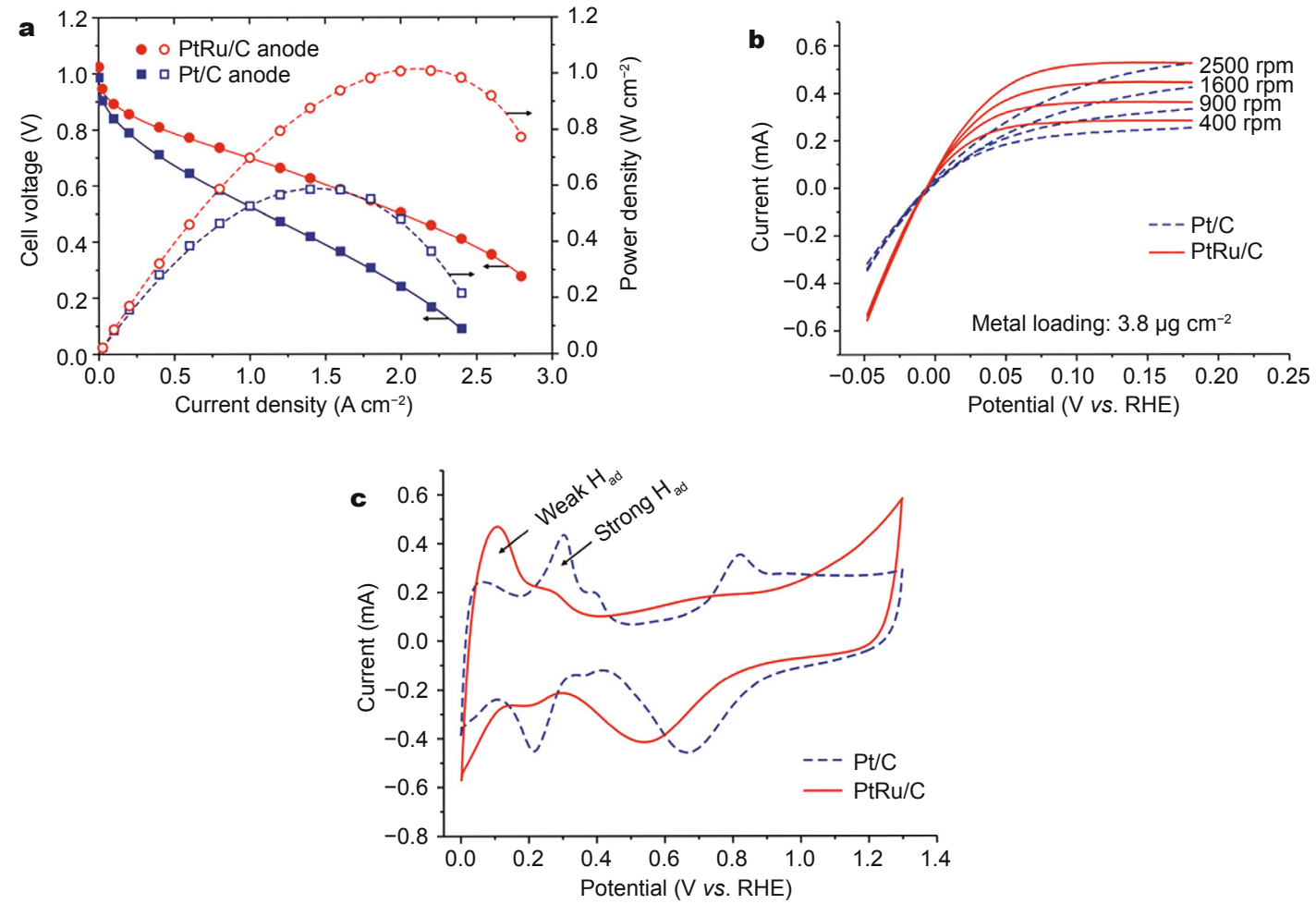

Figure 12 (a) Cell performance of the anion exchange membrane fuel cell using the PtRu anode or Pt anode. Metal loading in both the anode and the cathode is $0.4 \mathrm{mg} \mathrm{cm}^{-2}$. (b) $\mathrm{RDE}$ measurements in $\mathrm{H}_{2}$-saturated $0.1 \mathrm{~mol} \mathrm{~L}^{-1} \mathrm{KOH}$. (c) Cyclic voltammograms of Pt/C and PtRu/C in $0.1 \mathrm{~mol} \mathrm{~L}-1 \mathrm{KOH}$ solution. Reprinted with permission from Ref. [95] (Copyright 2015, the Royal Society of Chemistry).

tions, which provides the possibility of using non-precious metals as HOR/HER catalysts. In commercial alkaline fuel cells, Raney Ni has been used as the anode catalyst [102]. Raney $\mathrm{Ni}$ is functional under highly alkaline conditions (e.g., $6 \mathrm{~mol} \mathrm{~L}{ }^{-1} \mathrm{KOH}$ ), and the HOR activity can be further improved by fabrication of Ni alloys, such as NiMo $[97,103]$ and NiCr [104]. Fuel cells of this type have been successfully used in space. However, they are not stable on earth due to $\mathrm{CO}_{2}$ contamination. The $\mathrm{CO}_{2}$-contamination problem may potentially be resolved with the recently developed anion exchange membrane fuel cells that have been found application in daily life [11]. However, the Raney Ni-type catalysts are non-functional in the polymer electrolyte fuel cells due to the low activity [105]. A few attempts have been made to improve the HOR/HER activity of the Ni-based catalysts. Zhuang and co-authors [105] decorated $\mathrm{Ni}$ nanoparticles with $\mathrm{CrO}_{x}$ for application as the anode catalyst in an anion exchange membrane fuel cell to catalyze hydrogen oxidation. $\mathrm{CrO}_{x}$ is considered to weaken the binding of oxygen to the Ni nanoparticles, preventing the deactivation of $\mathrm{Ni}$ via oxidation. A fuel cell with a peak power density of $50 \mathrm{~mW} \mathrm{~cm} \mathrm{~cm}^{-2}$ is prepared without any no- ble metal catalysts (Fig. 13). Although the peak power density is still inadequate, this system illustrates the possibility of using a PGM-free catalyst as the anode in the polymer electrolyte fuel cell.

To further improve the catalytic activity, Yan and co-authors [98] electrochemically deposited NiCoMo on $\mathrm{Au}$ substrates. They showed that the optimal composition of $\mathrm{Co}_{0.12} \mathrm{Ni}_{5.1}$ Mo produced a high exchange current density of $0.015 \mathrm{~mA} \mathrm{~cm}^{-2}$. The high HOR/HER activity is attributed to the optimized hydrogen binding energy of the CoNi/ Mo surface, which is also confirmed by DFT calculation. To overcome the small-scale limitation of electrochemical deposition, Yan and co-authors [99] further developed non-precious metal HOR/HER catalysts through a wet chemistry method. Ni/C-CNT was synthesized through a two-step method: depositing $\mathrm{Ni}$ on the mildly oxidized CNT in solution followed by hydrothermal treatment. Figs $14 \mathrm{a}$ and $\mathrm{b}$ show the SEM and TEM images of the Ni/CCNTs. This catalyst exhibits enhanced HOR/HER activity relative to the pristine $\mathrm{Ni}$ nanoparticles or $\mathrm{Ni}$ supported on undoped CNTs (Figs 14c and d). The exchange current density of the Ni/N-CNT composite for the HOR is 0.028 


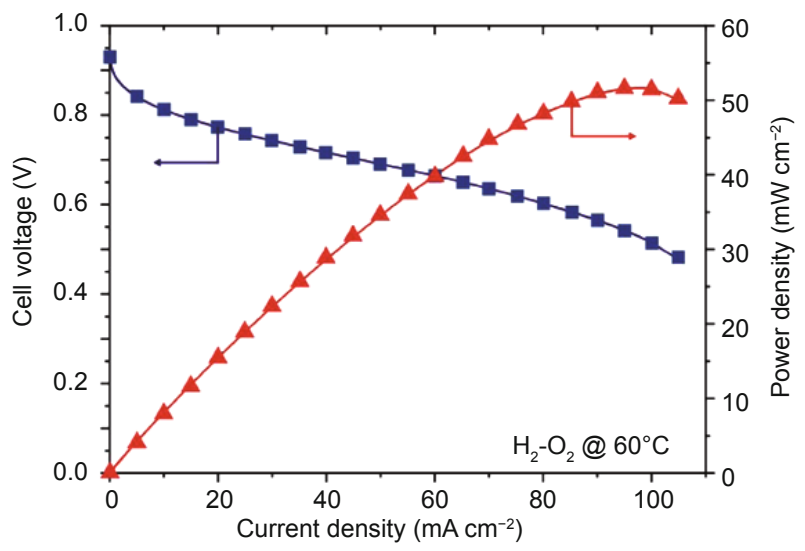

Figure 13 Cell performance of the PGM-free anion exchange membrane fuel cell using the $\mathrm{CrO}_{x}$-decorated $\mathrm{Ni}$ anode (Ni loading: $5 \mathrm{mg} \mathrm{cm}^{-2}$ ) and Ag cathode (Ag loading: $1 \mathrm{mg} \mathrm{cm}^{-2}$ ). Reprinted with permission from Ref. [105] (Copyright 2008, the National Academy of Sciences).
$\mathrm{mA} \mathrm{cm}{ }^{-2}$, which is similar to that of Pd. This enhanced HOR activity is attributed to the synergistic effect from the N-CNT support. Based on DFT calculations, the Ni nanoparticle is locally activated due to modulation of the $\mathrm{Ni}$ d orbitals when nitrogen dopants are present at the edge of the nanoparticle. Although, the activity of this catalyst is still one order of magnitude lower than that of the state-ofthe-art Pt catalyst, the lower cost makes it competitive in real applications.

Some reports have focused on the HER activity of the PGM-free catalyst in base. Ni alloys exhibit high HER activity in concentrated $\mathrm{KOH}$ electrolyte. An overpotential of only $70 \mathrm{mV}$ is required to achieve a current density of 20 $\mathrm{mA} \mathrm{cm}{ }^{-2}$ when NiMo nanopowder is utilized in $2 \mathrm{~mol} \mathrm{~L}^{-1}$ $\mathrm{KOH}$ [84]. Several HER catalysts have been reported to be active under lower alkalinity. Dai and co-authors [106] synthesized $\mathrm{NiO} / \mathrm{Ni}$ heterostructures on $\mathrm{CNT}$ for the HER a

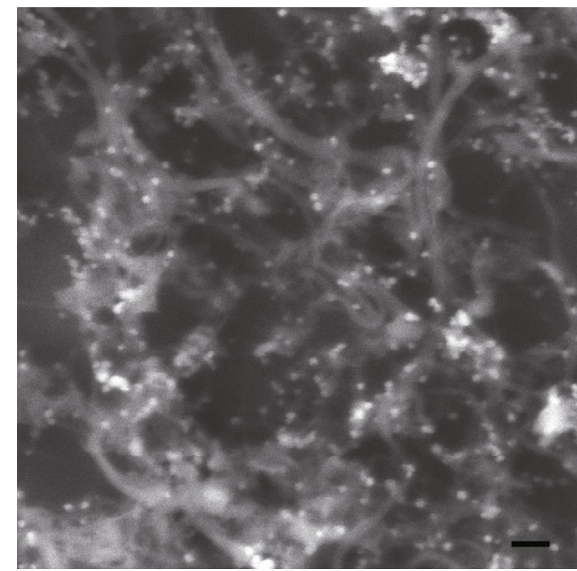

C

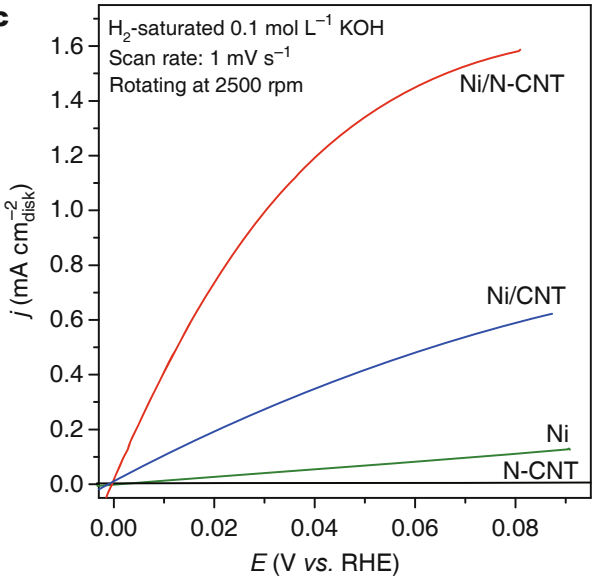

b
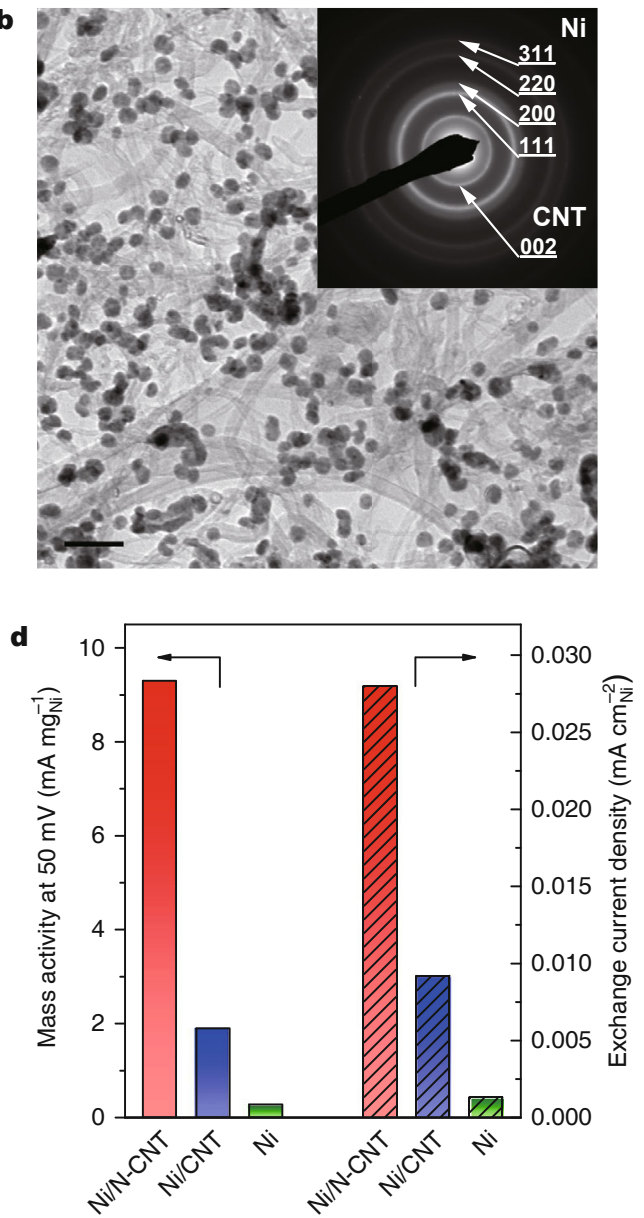

Figure 14 (a) SEM image of Ni/N-CNTs. Scale bar: $100 \mathrm{~nm}$. (b) TEM image of Ni/N-CNTs. Scale bar: $100 \mathrm{~nm}$. Inset shows selected area electron diffraction pattern. (c) Polarization curves of Ni/N-CNT, Ni/CNT, and Ni (all at a loading of $\left.0.25 \mathrm{mg}_{\mathrm{Ni}} \mathrm{cm}^{-2}\right)$ and N-CNT $\left(0.1 \mathrm{mg}_{\mathrm{C}} \mathrm{cm}^{-2}\right.$ ) catalysts in $\mathrm{H}_{2}$ saturated $0.1 \mathrm{~mol} \mathrm{~L}^{-1} \mathrm{KOH}$ at a scan rate of $1 \mathrm{mV} \mathrm{s}^{-1}$ using rotating speed of $2500 \mathrm{rpm}$. (d) Mass activity at $50 \mathrm{mV}$ (unpatterned) and exchange current density (patterned) of the $\mathrm{Ni} / \mathrm{N}-\mathrm{CNT}, \mathrm{Ni} / \mathrm{CNT}$, and Ni catalysts, respectively [99]. 
in base. The $\mathrm{Ni}$ cores are partially covered with small $\mathrm{NiO}$ nanoparticles. This heterojunction-like catalyst exhibits higher activity than the pristine Ni supported on CNT. Other than Ni, Wand and co-authors [107] reported that cobalt-cobalt oxide/N-doped carbon hybrids $\left(\mathrm{CoO}_{x} @ \mathrm{CN}\right)$ has an HER onset potential of $85 \mathrm{mV}$ in $1 \mathrm{~mol} \mathrm{~L}^{-1} \mathrm{KOH}$. However, this performance is still lower than that of the nickel-based catalysts.

Due to the stronger binding to hydrogen in base than in acid, PGMs exhibit lower HOR/HER activity in base. Alloys, core-shell structures, and hybrid hetero-structures have been developed to improve the activity of $\mathrm{Pt}$ in base. Significant enhancement has been achieved; however, the performance in base remains inferior to that in acid. The milder environment in base makes it possible to use non-precious metals as catalysts under basic conditions. Ni-based alloys or hybrid catalysts show acceptable HOR/ HER activity in base, comparable to that of the PGM catalysts. Anion exchange membrane fuel cells completely free from noble metal catalysts have been developed. Although the power density is still low, these systems show significant potential for the future.

\section{CONCLUSIONS AND OUTLOOK}

Though the hydrogen oxidation/evolution reaction is the simplest electrochemical reaction, it is essential to the hydrogen economy. The detailed mechanism of the HOR/ HER is still not clear; nevertheless, the hydrogen binding energy has generally been accepted as the descriptor of the HOR/HER activity in both acidic and basic electrolytes. Only catalysts with a hydrogen binding energy within an optimal zone exhibit high catalytic activity for the HOR/ HER. The binding energy of PGMs is influenced by the electrolyte. Increasing the basicity of the electrolyte results in stronger binding of hydrogen to Pt. The change in the hydrogen binding energy results in a slower HOR/HER rate in basic conditions than in acidic conditions. The development of high performance catalysts is desirable, and significant progress has been made in this area. Pt alloys and hybrid structures have been employed as HOR/HER catalysts for use under basic conditions, and several-fold enhancement of the activity has been achieved, although the activity of these species remains inferior to that of PGMs under acidic conditions. The development of PGMfree catalysts may largely reduce the cost of electrolyzers and fuel cells. Metal dichalcogenides and phosphides are good candidates to replace the costly Pt catalyst for the HER under acidic conditions. An overpotential of only 55 $\mathrm{mV}$ is required to achieve an HER current density of 10 $\mathrm{mA} \mathrm{cm}{ }^{-2}$ with FeP nanowires. However, there are no PGM- free HOR catalysts that are reported to be active in acid. In contrast, Ni-based PGM-free catalysts show both HOR and HER activity in base. PGM-free anion exchange membrane fuel cells have been reported, demonstrating that the PGMfree HOR catalysts do work in real applications. However, the activity is still over one order of magnitude lower than that of the state-of-the-art Pt catalyst.

There are several challenges for further developing HOR/HER catalysts. For real applications, highly active, cheap, and year-long stable catalysts are desired. Further development of HOR/HER catalysts may focus on, but not be limited to the following:

(i) In situ observation of the reaction processes. It is highly desirable to understand the reaction processes to provide guidance for the development of new catalysts. The HOR/HER is a good model to observe the electrochemical processes due to its simplicity. Because the reaction occurs on the surface of the catalysts, it is more desirable to observe the surface conditions. However, some powerful surface observation techniques, such as XPS, cannot be adapted to electrochemical reactions because of the presence of the electrolytes. A few spectroscopic techniques, such as infrared spectroscopy (IR) [108], Raman spectroscopy $[109,110]$, and extened X-ray absorption fine structure spectroscopy (EXAFS) [111] have been used to evaluate electrochemical reactions. Recently, in situ grazing incident $\mathrm{X}$ ray diffraction (GIXRD) has also been utilized to monitor phase transitions during electrochemical processes [112]. Based on these in situ observation techniques, the reaction mechanism of the HOR/HER may be understood in detail in the future, thereby providing guidance for the design of catalysts that can efficiently accelerate the rate-determining steps.

(ii) Identifying the active sites of the catalysts. Due to the complexity of the solid state catalysts, several types of sites (e.g., terraces, steps, edges, and defects) are simultaneously exposed. Thus, identifying the active sites is critical for understanding the reaction mechanism, and is also important for the design of new catalysts with more active sites. Model catalysts with specified exposed sites are beneficial for identification the active catalyst sites. Understanding of the active sites should make it possible to design and synthesize nanostructured particles with more active sites exposed to achieve higher activity.

(iii) Screening highly active non-precious metal catalysts. Low cost is a critical factor for practical application of catalysts. PGM-free catalysts are desired due to their low cost. However, to date, there is no PGM-free catalyst as active as Pt. As a futuristic approach, it may be possible to derive inspiration for catalyst design from enzymes, giv- 
en that a lot of enzymes have an active non-precious metal center. If these structures can be mimicked using nanoparticles, high HOR/HER activity might be obtained. Theoretical calculations have become a convenient and accurate tool in chemistry. By calculating the binding energy and the dynamics of the process, the HOR/HER activity can be predicted. There are several examples of new HOR/HER catalysts that are firstly predicted by DFT calculation and then confirmed by experiments $[85,89]$. It would be more efficient to screen catalysts assisted by theoretical calculations.

(iv) Developing nanostructured hybrid catalysts. Hybrid catalysts may have superior catalytic properties due to their synergistic effects $[113,114]$. The electronic and geometrical effects derived from the additional components may lead to optimal binding between the catalyst nanoparticles and the reactant, resulting in higher activity. However, controlled synthesis of the desired nanostructure is still challenging. As a benefit of the recent advances in nanostructure synthesis methodology, a series of hybrid nanostructures, such as core-shell, dimer, and heterostructures, can be controllably synthesized [113,115]. Therefore, novel high performance hybrid catalysts may potentially be realized in the future.

\section{Received 19 January 2016; accepted 10 February 2016;} published online 29 March 2016

1 Bockris JOM. A hydrogen economy. Science, 1972, 176: 1323-1323

2 Bockris JOM. Hydrogen economy in the future. Int J Hydrogen Energ, 1999, 24: 1-15

3 Bockris JOM. The hydrogen economy: its history. Int J Hydrogen Energ, 2013, 38: 2579-2588

4 Gasteiger HA, Kocha SS, Sompalli B, Wagner FT. Activity benchmarks and requirements for Pt, Pt-alloy, and non-Pt oxygen reduction catalysts for PEMFCs. Appl Catal B Environ, 2005, 56: 9-35

5 Wang Y, Zhao N, Fang B, et al. Carbon-supported Pt-based alloy electrocatalysts for the oxygen reduction reaction in polymer electrolyte membrane fuel cells: particle size, shape, and composition manipulation and their impact to activity. Chem Rev, 2015, 115: 3433-3467

6 Dai L, Xue Y, Qu L, Choi H, Baek J. Metal-free catalysts for oxygen reduction reaction. Chem Rev, 2015, 115: 4823-4892

7 Chen D, Chen C, Baiyee ZM, Shao Z, Ciucci F. Nonstoichiometric oxides as low-cost and highly-efficient oxygen reduction/evolution catalysts for low-temperature electrochemical devices. Chem Rev, 2015, 115: 9869-9921

8 Bing Y, Liu H, Zhang L, Ghosh D, Zhang J. Nanostructured Pt-alloy electrocatalysts for PEM fuel cell oxygen reduction reaction. Chem Soc Rev, 2010, 39: 2184-2202

9 Nie Y, Li L, Wei Z. Recent advancements in Pt and Pt-free catalysts for oxygen reduction reaction. Chem Soc Rev, 2015, 44: 2168-2201

10 Scofield ME, Liu H, Wong SS. A concise guide to sustainable PEMFCs: recent advances in improving both oxygen reduction catalysts and proton exchange membranes. Chem Soc Rev, 2015, 44: 5836-5860

11 Varcoe JR, Atanassov P, Dekel DR, et al. Anion-exchange mem- branes in electrochemical energy systems. Energ Environ Sci, 2014, 7: 3135-3191

12 Gasteiger HA, Markovic NM, Ross PN. $\mathrm{H}_{2}$ and CO Electrooxidation on well-characterized $\mathrm{Pt}, \mathrm{Ru}$, and $\mathrm{Pt}-\mathrm{Ru}$. 1. Rotating disk electrode studies of the pure gases including temperature effects. J Phys Chem, 1995, 99: 8290-8301

13 Zheng J, Zhuang Z, Xu B, Yan Y. Correlating hydrogen oxidation/ evolution reaction activity with the minority weak hydrogen-binding sites on Ir/C catalysts. ACS Catal, 2015, 5: 4449-4455

14 Sheng W, Gasteiger HA, Yang SH. Hydrogen oxidation and evolution reaction kinetics on platinum: acid $v s$. alkaline electrolytes. J Electrochem Soc, 2010, 157: B1529-B1536

15 Durst J, Simon C, Hasché F, Gasteiger HA. Hydrogen oxidation and evolution reaction kinetics on carbon supported $\mathrm{Pt}, \mathrm{Ir}, \mathrm{Rh}$, and Pd electrocatalysts in acidic media. J Electrochem Soc, 2015, 162: F190-F203

16 Durst J, Siebel A, Simon C, et al. New insights into the electrochemical hydrogen oxidation and evolution reaction mechanism. Energ Environ Sci, 2014, 7: 2255-2260

17 Neyerlin KC, Gu W, Jorne J, Gasteiger HA. Study of the exchange current density for the hydrogen oxidation and evolution reactions. J Electrochem Soc, 2007, 154: B631-B635

18 Uchida H, Izumi K, Aoki K, Watanabe M. Temperature-dependence of hydrogen oxidation reaction rates and $\mathrm{CO}$-tolerance at carbon-supported Pt, Pt-Co, and Pt-Ru catalysts. Phys Chem Chem Phys, 2009, 11: 1771-1779

19 Zhou J, Zu Y, Bard AJ. Scanning electrochemical microscopy: Part 39. The proton/hydrogen mediator system and its application to the study of the electrocatalysis of hydrogen oxidation. J Electroanal Chem, 2000, 491: 22-29

20 Zoski CG. Scanning electrochemical microscopy: investigation of hydrogen oxidation at polycrystalline noble metal electrodes. J Phys Chem B, 2003, 107: 6401-6405

21 Bagotzky VS, Osetrova NV. Investigations of hydrogen ionization on platinum with the help of micro-electrodes. J Electroanal Chem, 1973, 43: 233-249

22 Chen S, Kucernak A. Electrocatalysis under conditions of high mass transport: investigation of hydrogen oxidation on single submicron Pt particles supported on carbon. J Phys Chem B, 2004, 108: 13984-13994

23 Kucernak AR, Toyoda E. Studying the oxygen reduction and hydrogen oxidation reactions under realistic fuel cell conditions. Electrochem Commun, 2008, 10: 1728-1731

24 Zalitis CM, Kramer D, Kucernak AR. Electrocatalytic performance of fuel cell reactions at low catalyst loading and high mass transport. Phys Chem Chem Phys, 2013, 15: 4329-4340

25 Sun Y, Lu J, Zhuang L. Rational determination of exchange current density for hydrogen electrode reactions at carbon-supported $\mathrm{Pt}$ catalysts. Electrochim Acta, 2010, 55: 844-850

26 Barber J, Morin S, Conway BE. Specificity of the kinetics of $\mathrm{H}_{2}$ evolution to the structure of single-crystal Pt surfaces, and the relation between opd and upd H. J Electroanal Chem, 1998, 446: 125-138

27 Strmcnik D, Uchimura M, Wang C, et al. Improving the hydrogen oxidation reaction rate by promotion of hydroxyl adsorption. Nat Chem, 2013, 5: 300-306

28 Trasatti S. Work function, electronegativity, and electrochemical behaviour of metals: III. Electrolytic hydrogen evolution in acid solutions. J Electroanal Chem, 1972, 39: 163-184

29 Norskov JK, Bligaard T, Logadottir A, et al. Trends in the exchange current for hydrogen evolution. J Electrochem Soc, 2005, 152: J23J26

30 Sheng W, Myint M, Chen JG, Yan Y. Correlating the hydrogen evolution reaction activity in alkaline electrolytes with the hydrogen 
binding energy on monometallic surfaces. Energ Environ Sci, 2013, 6: $1509-1512$

31 Leonard KC, Bard AJ. Pattern recognition correlating materials properties of the elements to their kinetics for the hydrogen evolution reaction. J Am Chem Soc, 2013, 135: 15885-15889

32 Durst J, Siebel A, Simon C, et al. New insights into the electrochemical hydrogen oxidation and evolution reaction mechanism. Energ Environ Sci, 2014, 7: 2255-2260

33 Sheng W, Zhuang Z, Gao M, et al. Correlating hydrogen oxidation and evolution activity on platinum at different $\mathrm{pH}$ with measured hydrogen binding energy. Nat Commun, 2015, 6: 5848

34 Zheng J, Sheng W, Zhuang Z, Xu B, Yan Y. Universal dependence of hydrogen oxidation and evolution reaction activity of platinum-group-metals on $\mathrm{pH}$ and hydrogen binding energy. Sci Adv, 2016, 2: e1501602

35 McCrory CCL, Jung S, Ferrer IM, et al. Benchmarking hydrogen evolving reaction and oxygen evolving reaction electrocatalysts for solar water splitting devices. J Am Chem Soc, 2015, 137: 4347-4357

36 Zheng J, Yan Y, Xu B. Correcting the hydrogen diffusion limitation in rotating disk electrode measurements of hydrogen evolution reaction kinetics. J Electrochem Soc, 2015, 162: F1470-F1481

37 Kong D, Wang H, Cha JJ, et al. Synthesis of $\mathrm{MoS}_{2}$ and $\mathrm{MoSe}_{2}$ films with vertically aligned layers. Nano Lett, 2013, 13: 1341-1347

38 Yang Y, Fei H, Ruan G, Xiang C, Tour JM. Edge-oriented $\mathrm{MoS}_{2}$ nanoporous films as flexible electrodes for hydrogen evolution reactions and supercapacitor devices. Adv Mater, 2014, 26: 8163-8168

39 Lukowski MA, Daniel AS, Meng F, et al. Enhanced hydrogen evolution catalysis from chemically exfoliated metallic $\mathrm{MoS}_{2}$ nanosheets. J Am Chem Soc, 2013, 135: 10274-10277

40 Xie J, Zhang J, Li S, et al. Controllable disorder engineering in oxygen-incorporated $\mathrm{MoS}_{2}$ ultrathin nanosheets for efficient hydrogen evolution. J Am Chem Soc, 2013, 135: 17881-17888

41 Voiry D, Salehi M, Silva R, et al. Conducting $\mathrm{MoS}_{2}$ nanosheets as catalysts for hydrogen evolution reaction. Nano Lett, 2013, 13: 6222-6227

42 Kibsgaard J, Chen Z, Reinecke BN, Jaramillo TF. Engineering the surface structure of $\mathrm{MoS}_{2}$ to preferentially expose active edge sites for electrocatalysis. Nat Mater, 2012, 11: 963-969

43 Li Y, Wang $\mathrm{H}$, Xie L, et al. $\mathrm{MoS}_{2}$ nanoparticles grown on graphene: an advanced catalyst for the hydrogen evolution reaction. J Am Chem Soc, 2011, 133: 7296-7299

44 Chen Z, Cummins D, Reinecke BN, et al. Core-shell $\mathrm{MoO}_{3}-\mathrm{MoS}_{2}$ nanowires for hydrogen evolution: a functional design for electrocatalytic materials. Nano Lett, 2011, 11: 4168-4175

45 Xie J, Zhang H, Li S, et al. Defect-rich $\mathrm{MoS}_{2}$ ultrathin nanosheets with additional active edge sites for enhanced electrocatalytic hydrogen evolution. Adv Mater, 2013, 25: 5807-5813

46 Lu Z, Zhu W, Yu X, et al. Ultrahigh hydrogen evolution performance of under-water "superaerophobic" $\mathrm{MoS}_{2}$ nanostructured electrodes. Adv Mater, 2014, 26: 2683-2687

47 Gao MR, Chan MKY, Sun Y. Edge-terminated molybdenum disulfide with a 9.4- $\AA$ interlayer spacing for electrochemical hydrogen production. Nat Commun, 2015, 6: 7493

48 Yan Y, Xia B, Li N, et al. Vertically oriented $\mathrm{MoS}_{2}$ and $\mathrm{WS}_{2}$ nanosheets directly grown on carbon cloth as efficient and stable 3-dimensional hydrogen-evolving cathodes. J Mater Chem A, 2015, 3: $131-135$

49 Ge X, Chen L, Zhang L, et al. Nanoporous metal enhanced catalytic activities of amorphous molybdenum sulfide for high-efficiency hydrogen production. Adv Mater, 2014, 26: 3100-3104

50 Wang T, Liu L, Zhu Z, et al. Enhanced electrocatalytic activity for hydrogen evolution reaction from self-assembled monodispersed molybdenum sulfide nanoparticles on an Au electrode. Energ Envi- ron Sci, 2013, 6: 625-633

51 Cheng L, Huang W, Gong Q, et al. Ultrathin $\mathrm{WS}_{2}$ nanoflakes as a high-performance electrocatalyst for the hydrogen evolution reaction. Angew Chem Int Ed, 2014, 53: 7860-7863

52 Yang J, Voiry D, Ahn SJ, et al. Two-dimensional hybrid nanosheets of tungsten disulfide and reduced graphene oxide as catalysts for enhanced hydrogen evolution. Angew Chem Int Ed, 2013, 52: 13751-13754

53 Voiry D, Yamaguchi H, Li J, et al. Enhanced catalytic activity in strained chemically exfoliated $\mathrm{WS}_{2}$ nanosheets for hydrogen evolution. Nat Mater, 2013, 12: 850-855

54 Duan J, Sheng C, Chambers BA, Andersson GG, Zhang QS. 3D WS nanolayers@heteroatom-doped graphene films as hydrogen evolution catalyst electrodes. Adv Mater, 2015, 27: 4234-4241

55 Kong D, Cha JJ, Wang H, Lee HR, Cui Y. First-row transition metal dichalcogenide catalysts for hydrogen evolution reaction. Energ Environ Sci, 2013, 6: 3553-3558

56 Kong D, Wang H, Lu Z, Cui Y. CoSe $e_{2}$ nanoparticles grown on carbon fiber paper: an efficient and stable electrocatalyst for hydrogen evolution reaction. J Am Chem Soc, 2014, 136: 4897-4900

57 Faber MS, Dziedzic R, Lukowski MA, et al. High-performance electrocatalysis using metallic cobalt pyrite $\left(\mathrm{CoS}_{2}\right)$ micro- and nanostructures. J Am Chem Soc, 2014, 136: 10053-10061

58 Long X, Li G, Wang Z, et al. Metallic iron-nickel sulfide ultrathin nanosheets as a highly active electrocatalyst for hydrogen evolution reaction in acidic media. J Am Chem Soc, 2015, 137: 11900-11903

59 Wang D, Gong M, Chou H, et al. Highly active and stable hybrid catalyst of cobalt-doped $\mathrm{FeS}_{2}$ nanosheets-carbon nanotubes for hydrogen evolution reaction. J Am Chem Soc, 2015, 137: 1587-1592

60 Popczun EJ, McKone JR, Read CG, et al. Nanostructured nickel phosphide as an electrocatalyst for the hydrogen evolution reaction. J Am Chem Soc, 2013, 135: 9267-9270

61 Zhuo J, Cabán-Acevedo M, Liang H, et al. High-performance electrocatalysis for hydrogen evolution reaction using Se-doped pyrite-phase nickel diphosphide nanostructures. ACS Catal, 2015, 5: 6355-6361

62 Popczun EJ, Read CG, Roske CW, Lewis NS, Schaak RE. Highly active electrocatalysis of the hydrogen evolution reaction by cobalt phosphide nanoparticles. Angew Chem Int Ed, 2014, 53: 5427-5430

63 Yang H, Zhang Y, Hu F, Wang Q. Urchin-like CoP nanocrystals as hydrogen evolution reaction and oxygen reduction reaction dual-electrocatalyst with superior stability. Nano Lett, 2015, 15: 7616-7620

64 Tian J, Liu Q, Asiri AM, Sun X. Self-supported nanoporous cobalt phosphide nanowire arrays: an efficient 3D hydrogen-evolving cathode over the wide range of $\mathrm{pH}$ 0-14. J Am Chem Soc, 2014, 136: 7587-7590

65 Liu Q, Tian J, Cui W, et al. Carbon nanotubes decorated with CoP nanocrystals: a highly active non-noble-metal nanohybrid electrocatalyst for hydrogen evolution. Angew Chem Int Ed, 2014, 53: 6710-6714

66 Yang Y, Fei H, Ruan G, Tour JM. Porous cobalt-based thin film as a bifunctional catalyst for hydrogen generation and oxygen generation. Adv Mater, 2015, 27: 3175-3180

67 Jiang P, Liu Q, Liang Y, et al. A cost-effective 3D hydrogen evolution cathode with high catalytic activity: FeP nanowire array as the active phase. Angew Chem Int Ed, 2014, 53: 12855-12859

68 Yan Y, Xia BY, Ge X, et al. A flexible electrode based on iron phosphide nanotubes for overall water splitting. Chem Eur J, 2015, 21 : 18062-18067

69 Xiao P, Sk MA, Thia L, et al. Molybdenum phosphide as an efficient electrocatalyst for the hydrogen evolution reaction. Energ Environ Sci, 2014, 7: 2624-2629 
70 Xing Z, Liu Q, Asiri AM, Sun X. Closely interconnected network of molybdenum phosphide nanoparticles: a highly efficient electrocatalyst for generating hydrogen from water. Adv Mater, 2014, 26: 5702-5707

71 Kibsgaard J, Jaramillo TF. Molybdenum phosphosulfide: an active, acid-stable, earth-abundant catalyst for the hydrogen evolution reaction. Angew Chem Int Ed, 2014, 53: 14433-14437

72 Tian J, Liu Q, Cheng N, Asiri AM, Sun X. Self-supported $\mathrm{Cu}_{3} \mathrm{P}$ nanowire arrays as an integrated high-performance three-dimensional cathode for generating hydrogen from water. Angew Chem Int Ed, 2014, 53: 9577-9581

73 Chen W, Sasaki K, Ma C, et al. Hydrogen-evolution catalysts based on non-noble metal nickel-molybdenum nitride nanosheets. Angew Chem Int Ed, 2012, 51: 6131-6135

74 Cao B, Veith GM, Neuefeind JC, Adzic RR, Khalifah PG. Mixed close-packed cobalt molybdenum nitrides as non-noble metal electrocatalysts for the hydrogen evolution reaction. J Am Chem Soc, 2013, 135: 19186-19192

75 Vrubel H, Hu X. Molybdenum boride and carbide catalyze hydrogen evolution in both acidic and basic solutions. Angew Chem Int Ed, 2012, 51: 12703-12706

76 Liao L, Wang S, Xiao J, et al. A nanoporous molybdenum carbide nanowire as an electrocatalyst for hydrogen evolution reaction. Energ Environ Sci, 2014, 7: 387-392

77 Chen WF, Wang $\mathrm{CH}$, Sasaki $\mathrm{K}$, et al. Highly active and durable nanostructured molybdenum carbide electrocatalysts for hydrogen production. Energ Environ Sci, 2013, 6: 943-951

78 Xiao P, Ge X, Wang H, et al. Novel molybdenum carbide-tungsten carbide composite nanowires and their electrochemical activation for efficient and stable hydrogen evolution. Adv Funct Mater, 2015, 25: $1520-1526$

79 Wu R, Zhang J, Shi Y, Liu D, Zhang B. Metallic $\mathrm{WO}_{2}$-carbon mesoporous nanowires as highly efficient electrocatalysts for hydrogen evolution reaction. J Am Chem Soc, 2015, 137: 6983-6986

80 Zheng Y, Jiao Y, Zhu Y, et al. Hydrogen evolution by a metal-free electrocatalyst. Nat Commun, 2014, 5: 3783

81 Xu Y, Gao M, Zheng Y, Jiang J, Yu S. Nickel/nickel(II) oxide nanoparticles anchored onto cobalt (IV) diselenide nanobelts for the electrochemical production of hydrogen. Angew Chem Int Ed, 2013, 52: 8546-8550

82 Zhu H, Zhang J, Yanzhang R, et al. When cubic cobalt sulfide meets layered molybdenum disulfide: a core-shell system toward synergetic electrocatalytic water splitting. Adv Mater, 2015, 27: 4752-4759

83 Wang Z, Hao X, Jiang Z, et al. C and $\mathrm{N}$ hybrid coordination derived Co-C-N complex as a highly efficient electrocatalyst for hydrogen evolution reaction. J Am Chem Soc, 2015, 137: 15070-15073

84 McKone JR, Sadtler BF, Werlang CA, Lewis NS, Gray HB. Ni-Mo nanopowders for efficient electrochemical hydrogen evolution. ACS Catal, 2013, 3: 166-169

85 Berit H, Poul Georg M, Jacob B, et al. Biomimetic hydrogen evolution: $\mathrm{MoS}_{2}$ nanoparticles as catalyst for hydrogen evolution. J Am Chem Soc, 2005, 127: 5308-5309

86 Jaramillo TF, Jørgensen KP, Bonde J, et al. Identification of active edge sites for electrochemical $\mathrm{H}_{2}$ evolution from $\mathrm{MoS}_{2}$ nanocatalysts. Science, 2007, 317: 100-102

87 Jaramillo TF, Bonde J, Zhang J, et al. Hydrogen evolution on supported incomplete cubane-type $\left[\mathrm{Mo}_{3} \mathrm{~S}_{4}\right]^{4+}$ electrocatalysts. J Phys Chem C, 2008, 112: 17492-17498

88 Karunadasa HI, Montalvo E, Sun Y, et al. A molecular $\mathrm{MoS}_{2}$ edge site mimic for catalytic hydrogen generation. Science, 2012, 335: 698-702

89 Ping L, Rodriguez JA. Catalysts for hydrogen evolution from the [NiFe] hydrogenase to the $\mathrm{Ni}_{2} \mathrm{P}(001)$ surface: the importance of en- semble effect. J Am Chem Soc, 2005, 127: 14871-14878

90 Wan C, Regmi YN, Leonard BM. Multiple phases of molybdenum carbide as electrocatalysts for the hydrogen evolution reaction. Angew Chem Int Ed, 2014, 53: 6407-6410

91 Gao MR, Liang JX, Zheng YR, et al. An efficient molybdenum disulfide/cobalt diselenide hybrid catalyst for electrochemical hydrogen generation. Nat Commun, 2015, 6: 5982

92 Winther-Jensen B, Fraser K, Ong C, Forsyth M, MacFarlane DR. Conducting polymer composite materials for hydrogen generation. Adv Mater, 2010, 22: 1720-1727

$93 \mathrm{Gu}$ C, Norris BC, Fan FRF, Bielawski CW, Bard AJ. Is base-inhibited vapor phase polymerized PEDOT an electrocatalyst for the hydrogen evolution reaction? Exploring substrate effects, including Pt contaminated Au. ACS Catal, 2012, 2: 746-750

94 Alia SM, Pivovar BS, Yan Y. Platinum-coated copper nanowires with high activity for hydrogen oxidation reaction in base. J Am Chem Soc, 2013, 135: 13473-13478

95 Wang Y, Wang G, Li G, et al. Pt-Ru catalyzed hydrogen oxidation in alkaline media: oxophilic effect or electronic effect? Energ Environ Sci, 2015, 8: 177-181

96 Mund K, Richter G, von Sturm F. Titanium-containing raney nickel catalyst for hydrogen electrodes in alkaline fuel cell systems. J Electrochem Soc, 1977, 124: 1-6

97 Fan C, Piron DL, Sleb A, Paradis P. Study of electrodeposited nickel-molybdenum, nickel-tungsten, cobalt-molybdenum, and cobalt-tungsten as hydrogen electrodes in alkaline water electrolysis. J Electrochem Soc, 1994, 141: 382-387

98 Sheng W, Bivens AP, Myint M, et al. Non-precious metal electrocatalysts with high activity for hydrogen oxidation reaction in alkaline electrolytes. Energ Environ Sci, 2014, 7: 1719-1724

99 Zhuang Z, Giles SA, Zheng J, et al. Nickel supported on nitrogen-doped carbon nanotubes as hydrogen oxidation reaction catalyst in alkaline electrolyte. Nat Commun, 2016, 7: 10141

100 Elbert K, Hu J, Ma Z, et al. Elucidating hydrogen oxidation/evolution kinetics in base and acid by enhanced activities at the optimized Pt shell thickness on the Ru core. ACS Catal, 2015, 5: 6764-6772

101 Ram S, Dusan T, Dusan S, et al. Enhancing hydrogen evolution activity in water splitting by tailoring $\mathrm{Li}^{\oplus}-\mathrm{Ni}(\mathrm{OH})_{2}-\mathrm{Pt}$ interfaces. Science, 2011, 334: 1256-1260

102 Jenseit W, Khalil A, Wendt H. Material properties and processing in the production of fuel cell components: I. Hydrogen anodes from Raney nickel for lightweight alkaline fuel cells. J Appl Electrochem, 1990, 20: 893-900

103 Raj IA, Vasu KI. Transition metal-based hydrogen electrodes in alkaline solution-electrocatalysis on nickel based binary alloy coatings. J Appl Electrochem, 1990, 20: 32-38

104 Kiros Y, Majari M, Nissinen TA. Effect and characterization of dopants to Raney nickel for hydrogen oxidation. J Alloy Compd, 2003, 360: 279-285

105 Lu S, Pan J, Huang A, Zhuang L, Lu J. Alkaline polymer electrolyte fuel cells completely free from noble metal catalysts. Proc Natl Acad Sci USA, 2008, 105: 20611-20614

106 Gong M, Zhou W, Tsai M, et al. Nanoscale nickel oxide/nickel heterostructures for active hydrogen evolution electrocatalysis. Nat Commun, 2014, 5: 4695

107 Jin H, Wang J, Su D, et al. In situ cobalt-cobalt oxide/N-doped carbon hybrids as superior bifunctional electrocatalysts for hydrogen and oxygen evolution. J Am Chem Soc, 2015, 137: 2688-2694

108 Zhang M, de Respinis M, Frei H. Time-resolved observations of water oxidation intermediates on a cobalt oxide nanoparticle catalyst. Nat Chem, 2014, 6: 362-367

109 Yeo BS, Bell AT. In situ Raman study of nickel oxide and gold-supported nickel oxide catalysts for the electrochemical evolution of 
oxygen. J Phys Chem C, 2012, 116: 8394-8400

110 Kornienko N, Resasco J, Becknell N, et al. Operando spectroscopic analysis of an amorphous cobalt sulfide hydrogen evolution electrocatalyst. J Am Chem Soc, 2015, 137: 7448-7455

111 Landon J, Demeter E, İnoğlu N, et al. Spectroscopic characterization of mixed Fe-Ni oxide electrocatalysts for the oxygen evolution reaction in alkaline electrolytes. ACS Catal, 2012, 2: 1793-1801

112 Tung C, Hsu Y, Shen Y, et al. Reversible adapting layer produces robust single-crystal electrocatalyst for oxygen evolution. Nat Commun, 2015, 6: 8106

113 Cortie MB, McDonagh AM. Synthesis and optical properties of hybrid and alloy plasmonic nanoparticles. Chem Rev, 2011, 111 3713-3735

114 Liang Y, Li Y, Wang H, Dai H. Strongly coupled inorganic/nanocar- bon hybrid materials for advanced electrocatalysis. J Am Chem Soc, 2013, 135: 2013-2036

115 Donega CDM. Synthesis and properties of colloidal heteronanocrystals. Chem Soc Rev, 2011, 40: 1512-1546

Acknowledgment This work was supported by the State Key Laboratory of Organic-Inorganic Composites, Beijing University of Chemical Technology (oic-201503003).

Author contributions Zhuang Z designed the outlines; Lu S and Zhuang $\mathrm{Z}$ searched the reference papers and wrote the paper.

Conflict of interest The authors declare that they have no conflict of interest.

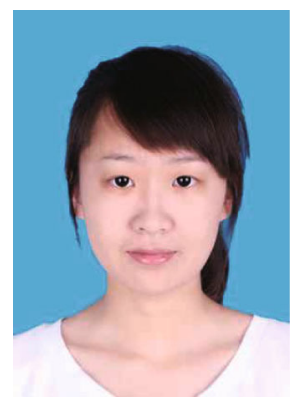

Siqi Lu was born in 1992. She is currently a PhD candidate at Beijing University of Chemical Technology under the supervision of Prof. Zhongbin Zhuang. Her research interests include electrocatalysts for electrochemical devices such as fuel cells.

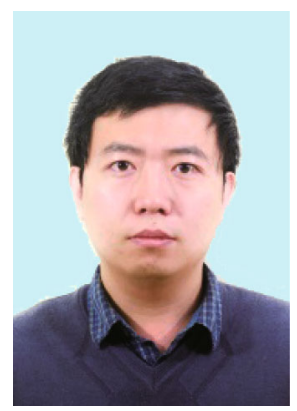

Zhongbin Zhuang was born in 1983. He received BSc and PhD degrees from the Department of Chemistry, Tsinghua University in 2005 and 2010, respectively. After postdoctoral work at the University of California, Riverside, and the University of Delaware, he joined Beijing University of Chemical Technology as a professor in 2015. His current research interests include electrocatalysts for fuel cells and electrolyzers, interfacial electrochemistry, and methodology for nanocrystal synthesis.

\section{氢气氧化/析出反应电催化剂}

卢思奇, 庄仲滨

摘要 氢经济以氢气作为能量载体, 是一个清洁、高效、可持续发展的能源体系. 电解池和燃料电池分别用于生产和消费氢气, 分别发生氢气析 出反应和氢气氧化反应. 催化剂是加速这两个反应进程的关键. 铂是目前最好的氢气析出和氢气氧化反应的催化剂, 但是铂的稀有性阻碍了其 实用化的进程. 因此, 开发更高活性的催化剂以减少铂用量, 或开发非贵金属催化剂替代铂成为了目前研究的重点. 本综述针对氢气析出与氢气 氧化反应, 讨论了反应的机制、影响催化剂活性的因素以及电解质 (酸性、碱性) 对催化过程的影响, 并按照酸性条件适用和碱性条件适用总结 了近年来在氢气析出与氢气氧化反应催化剂开发方面的进展. 